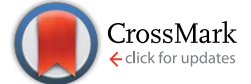

Cite this: RSC Adv., 2017, 7, 17559

Received 23rd January 2017 Accepted 16th March 2017

DOI: $10.1039 / \mathrm{c} 7 \mathrm{ra0} 01034 \mathrm{f}$

rsc.li/rsc-advances

\title{
Plasmonic nanoparticles in chemical analysis
}

\author{
Jan Krajczewski, Karol Kołątaj and Andrzej Kudelski*
}

Many very sensitive analytical methods utilising specific properties of plasmonic metal nanoparticles have been developed. Some of these techniques are so sensitive that observation of the reliable signal even from a single molecule of the analyte is possible. In this review article we present the most important analytical techniques based on the plasmonic properties of selected metal nanoparticles and the basic theoretical background of these analytical techniques, including the mechanism of the interaction of the electromagnetic radiation with the plasmonic nanoparticles. The analytical techniques presented in this article include methods based on the change of the optical properties of plasmonic nanoparticles caused by analyte-induced aggregation, etching or the change of the growth of plasmonic nanoparticles, and techniques utilising increased efficiency of some optical processes in the proximity of the plasmonic nanoparticles, e.g. surface-enhanced Raman scattering (SERS), surface enhanced infra-red absorption (SEIRA), and metal enhanced fluorescence (MEF). Recently, an observed increase in the number of applications of techniques utilising surface plasmon resonance for the analysis of various industrial, biological, medical, and environmental samples allows us to predict a large increase of the significance of these techniques in the near future.

\section{Introduction}

When electromagnetic radiation interacts with metal nanoparticles with a negative real and small positive imaginary dielectric constant (e.g. silver and gold nanoparticles) it induces a collective oscillation of surface conduction electrons called surface plasmons. ${ }^{1-5}$ Excitation of surface plasmons leads to an enhanced electromagnetic field at some places on the illuminated nanoparticles. Surface plasmons excited in silver and gold nanoparticles during their interaction with light are also responsible for the bright colours of $\mathrm{Ag}$ and $\mathrm{Au}$ colloids. The

Department of Chemistry, Faculty of Chemistry, University of Warsaw, Pasteur 1, 02-093 Warsaw, Poland. E-mail: akudel@chem.uw.edu.pl; Fax: +48-225526434 intensive colour of suspensions of $\mathrm{Ag}$ and $\mathrm{Au}$ nanoparticles was the reason for using these materials in ancient times. For example, in ancient Rome gold and silver nanoparticles were used (of course without an understanding of the phenomenon) for dyeing glass and ceramics. Such use of nanoparticles continued over time and many examples of stained glasses dyed using nanoparticles can be found in churches from the Middle Ages. Various colours of glass were obtained by the formation of nanoparticles with different diameters. For example, red glass often contained $c a .20 \mathrm{~nm}$ gold nanoparticles, pink glass contained $c a .30 \mathrm{~nm}$ gold nanoparticles and orange glass contained gold nanoparticles larger than $80 \mathrm{~nm}$ or silver nanoparticles. This method of glass dyeing is so durable that glass dyed centuries ago is still colourful.

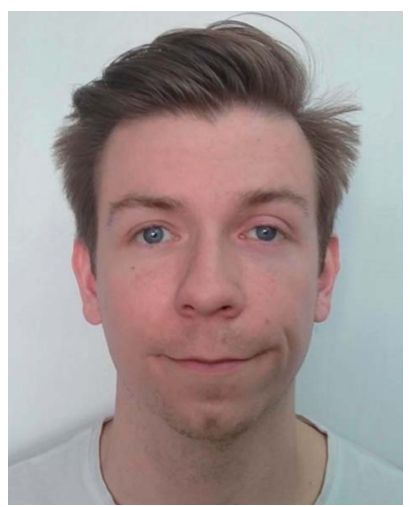

Jan Krajczewski is pursuing his PhD at the University of Warsaw, Poland. His main research interest is surface-enhanced Raman spectroscopy (SERS) and synthesis of various silver and gold nanoresonators.

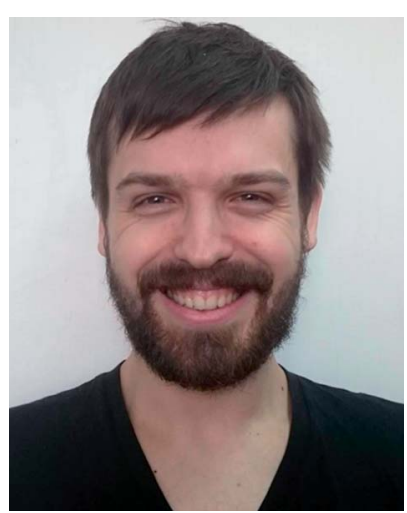

Karol Kolataj is pursuing his PhD at the University of Warsaw, Poland. His main research interest is shell-isolated nanoparticle-enhanced Raman spectroscopy (SHINERS) and synthesis of electromagnetic nanoresonators for SHINERS measurements. 
In this work some analytical applications of plasmonic metal nanoparticles are reviewed. We have focused on analytical applications based on the change of the plasmonic properties of $\mathrm{Ag}$ and $\mathrm{Au}$ nanoparticles caused by analyte-induced aggregation, etching or change of the grow of plasmonic nanoparticles, and on the analytical methods utilising increase of the efficiency of various optical processes in the proximity of gold and silver nanoparticles, such as surface-enhanced Raman scattering (SERS), surface enhanced infra-red absorption (SEIRA), and metal enhanced fluorescence (MEF) ${ }^{6,7}$ We have also briefly described the mechanism of the interaction of the electromagnetic wave with the plasmonic nanoobjects. All mentioned above plasmonic properties of gold and silver are only observed when gold and silver structures have sizes in the nanometers range (or the $\mathrm{Au} / \mathrm{Ag}$ surface is nanostructured). The appearance of new functionalities of materials after decreasing the size of its individual parts into the nanometers range is a realization of the futuristic concept of Richard Feynman presented in 1959 in the speech called: "There's Plenty of Room at the Bottom". In this lecture Feynman described some new possibilities that comes from use of systems in the nanometric scale. Futuristic nanotechnology idea described in 1959 by Feynman is today's reality and presented in this work applications of gold and silver nanoparticles is only a small part of the practical applications of nanomaterials.

\section{Surface plasmon resonance (SPR) and distribution of electromagnetic field around spherical "plasmonic" nanoparticles}

Optical properties of nanoparticles from IB metals are very important for many of their applications. While a gold ingot is yellow and a silver ingot is greyish, colour of $\mathrm{Au}$ and $\mathrm{Ag}$ nanoparticles strongly depends on their size and shape, and can have all colours of rainbow from red through green to violet. ${ }^{8}$ Silver and gold nanoparticles have their intensive and various colours because of plasmons excited on their surfaces. Metal can be considered as positively charged atomic nuclei surrounded by a plasma of free electrons from the conduction band. Surface plasmon resonance (SPR) is a collective oscillation of electron

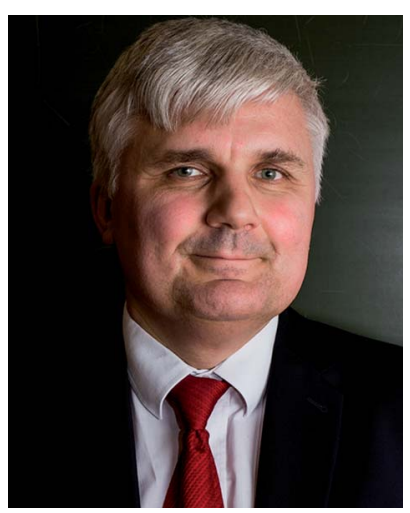

Andrzej Kudelski is a professor at the University of Warsaw, Poland. His area of expertise is vibrational spectroscopy of molecules at metal surfaces, mainly SERS, SHINERS, SEROA and SEIRA spectroscopy and synthesis of electromagnetic nanoresonators for various surface-enhanced vibrational spectroscopy. plasma near nanoparticle's surface when the nanoparticle is irradiated - see Fig. 1a.9,10

Dislocation of metal electrons in the nanoparticle during irradiation leads to creation of the electric dipole and, as a consequence, to the additional electric field near the nanoparticle's surface. The combined electric field depends on the electric field of the irradiating electromagnetic wave and on the field created near nanoparticle's surface by the surface plasmon resonance. For a spherical nanoparticle the electric field outside its surface is described by the following equation:

a)

b)
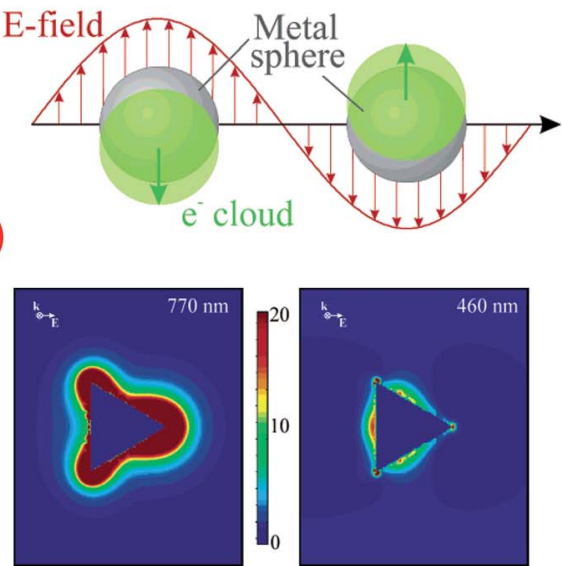

c)

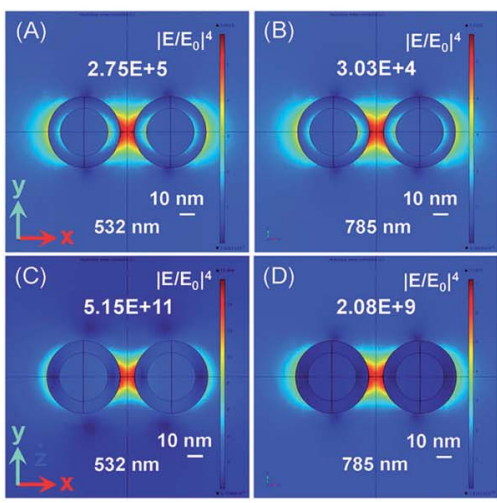

Fig. 1 (a) Schematic of plasmon oscillation in spherical plasmonic nanoparticle showing the displacement of the conduction electron charge cloud relative to the nuclei. Reprinted with permission from ref. 10. Copyright 2003 American Chemical Society. (b) Electric field enhancement contours around the silver trigonal prism for a plane that is perpendicular to the trigonal axis and that passes midway through the prism. The prism is illuminated by the light that have $\mathrm{k}$ along the trigonal axis and $\mathrm{E}$ along the abscissa. The size of the prism: side length $=100 \mathrm{~nm}$, thickness $=16 \mathrm{~nm}$. The wavelength of the excitation radiation: for the left image $770 \mathrm{~nm}$, and for the right image $460 \mathrm{~nm}$. Reprinted with permission from ref. 10. Copyright 2003 American Chemical Society. (c) Electromagnetic field distribution in the dimers consisting of two types of nanoparticles: (A) and (B) Silver nanoparticles $(30 \mathrm{~nm})$ with a thin silica layer $(5 \mathrm{~nm})$ and $(C)$ and (D) silica nanoparticles $(30 \mathrm{~nm})$ with a thin silver layer $(5 \mathrm{~nm})$ at two excitation wavelength ( $532 \mathrm{~nm}$ and $785 \mathrm{~nm}$ ). Reprinted with permission from ref. 31. Copyright 2015 the Owner Societies of PCCP. 


$$
E_{\text {out }}=E_{\mathrm{o}} \vec{x}-\alpha E_{\mathrm{o}}\left[\frac{\vec{x}}{r^{3}}-\frac{3 x}{r^{5}}(x \vec{x}+y \vec{y}+z \vec{z})\right]
$$

where $E_{\mathrm{o}}$ is the magnitude of the external electric field (pointing along the $x$-axis), $\alpha$ is the metal polarizability, $x, y, z$ are Cartesian coordinates, $r$ is the radial distance, and $\vec{x}, \vec{y}, \vec{z}$ are unit vectors. ${ }^{10,11}$ As can be seen, the first part of the above equation is the electric field of irradiating light and the second part is the electric field from the induced dipole created on the nanoparticle's surface. For a nanoparticle with a spherical geometry polarizability $\alpha$ can be expressed as:

$$
\begin{gathered}
\alpha=g_{\mathrm{d}} a^{3} \\
g_{\mathrm{d}}=\frac{\epsilon_{\mathrm{i}}-\epsilon_{\mathrm{o}}}{\epsilon_{\mathrm{i}}+2 \epsilon_{\mathrm{o}}}
\end{gathered}
$$

where $a$ is a radius of specific nanoparticle, $\epsilon_{\mathrm{i}}$ is the electric permittivity of the metal and $\epsilon_{\mathrm{o}}$ is the electric permittivity of nanoparticle's environment. ${ }^{10,11}$ As we can see from the above equations, the strongest surface plasmon resonance occurs when $\epsilon_{\mathrm{i}}=-2 \epsilon_{0}$, so for nanoparticles with strong plasmonic activity we can anticipate the existence of a band on the UV-vis extinction spectrum..$^{12}$ Moreover, for effective surface plasmon resonance the imaginary part of the dielectric permittivity (which is due to absorption) must be small. Such conditions are fulfilled only by nanoparticles from a few metals (for example $\mathrm{Au}, \mathrm{Ag}, \mathrm{Cu}, \mathrm{Al}$ ) and in this group silver nanoparticles has the greatest capacity to support surface plasmon resonance when using visible radiation. ${ }^{13}$

The incident electromagnetic wave irradiating nanoparticles is absorbed and scattered. Hence, the observed extinction of radiation by metal sols is the sum of these two phenomena: absorption and scattering. Absorption and scattering cross-section for spherical nanoparticles with radius $a$ are expressed as:

$$
C_{\mathrm{abs}}=4 \pi k a^{3} \operatorname{Im}\left[\left(\epsilon-\epsilon_{\mathrm{m}}\right) /\left(\epsilon+2 \epsilon_{\mathrm{m}}\right)\right]
$$

$$
C_{\text {sca }}=8 \pi / 3 k^{4} a^{6}\left[\left(\epsilon-\epsilon_{\mathrm{m}}\right) /\left(\epsilon+2 \epsilon_{\mathrm{m}}\right)\right]^{2}
$$

where $k=2 \pi / \lambda$ and $\lambda$ is wavelength. As can be seen from equations above $C_{\text {abs }}$ scales with $a^{3}$ while $C_{\text {sca }}$ scales with $a^{6}{ }^{6}{ }^{14}$ It means that absorption is more important for smaller nanoparticles (for such nanoparticles scattering can be neglected) while for larger nanoparticles light scattering becomes dominant. ${ }^{14}$

Surface plasmon resonance depends on many parameters of the nanoparticle, such as: its size and shape (Fig. 2 shows various nanoparticles practically used for SERS measurements in our group, see also ref. 15 and 16 for other examples), dielectric properties of the metal from which the nanoparticle is created, and the dielectric permittivity of the environment. ${ }^{17,18}$ Nanoparticles may have different plasmon modes (for more detailed description of the excitation of plasmons, the reader is referred to ref. 1 and 2). For small spherical nanoparticles only dipole plasmons are excited whereas for anisotropic nanoparticles also higher order plasmon modes can be excited..$^{19}$ For example, UV-vis absorption spectrum of silver nanoprisms obtained by the plasmon-driven transformation revealed three peaks: at $340 \mathrm{~nm}$ (out of plane quadrupole resonance), $470 \mathrm{~nm}$ (in-plane quadrupole resonance), and $640 \mathrm{~nm}$ (in-plane dipole resonance).$^{20}$ In the case of nanorods there are usually two separated absorption bands, one from the longitudinal excitation, and the second from the transverse excitation. Let us assume that the width of obtained nanorods is constant, and the length is changing. In this case the wavelength of the transverse mode is constant (for example $400 \mathrm{~nm}$ ) and the wavelength of the longitudinal excitation is blue shifted when the length of the nanorod is decreasing. When both dimensions are the same (nanoparticles are spherical) only one peak in spectrum is present. In general nanorods may reveal many multipole modes: dipoles, tripoles, quadrupoles, pentapoles, hexapoles, and even heptapoles, the position of these modes strongly depends on the size and the aspect ratios (length/ width) of the nanorod and is usually red shifted when the size of the nanorod is increasing. ${ }^{21}$

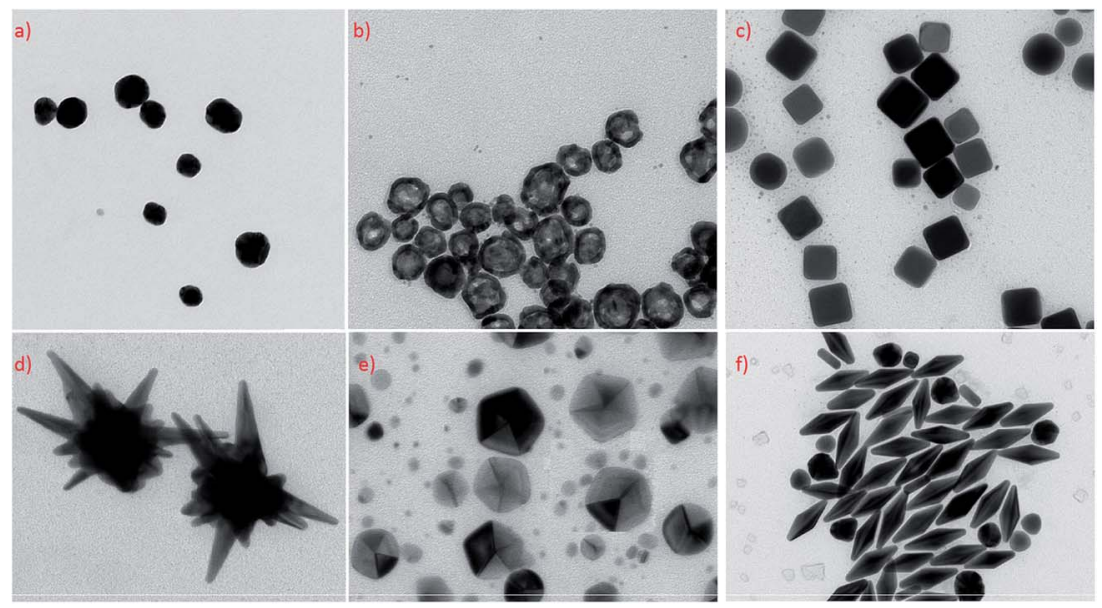

Fig. 2 TEM micrographs presenting Ag and Au nanoparticles with different geometry and shapes practically used as electromagnetic nanoresonators for SERS measurements: (a) quasi-spherical silver nanoparticles, (b) hollow spherical silver nanoparticles, (c) cubic silver nanoparticles, (d) gold-silver nanostars, (e) silver decahedral nanoparticles, (f) gold bipyramid. 


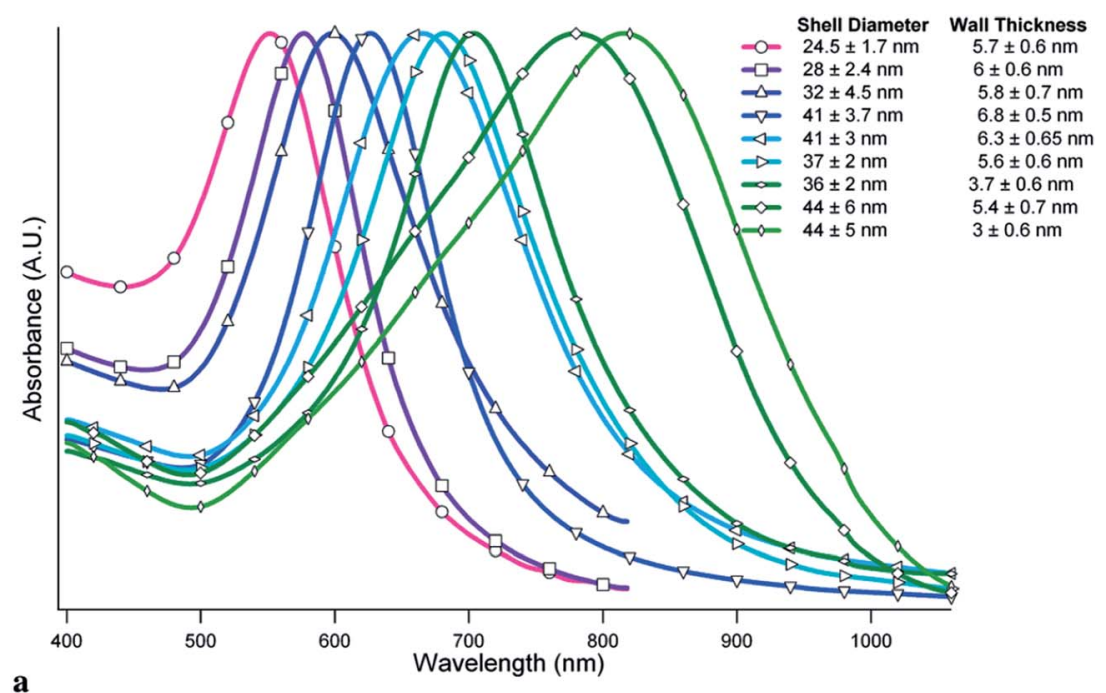

a

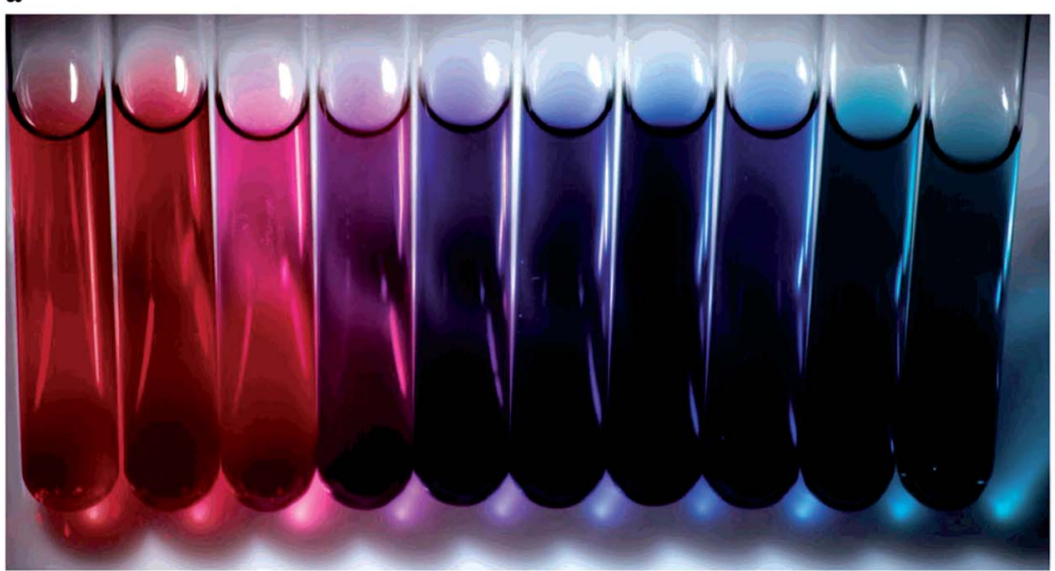

b

Fig. 3 (a) UV-visible absorption spectra of samples of gold hollow nanospheres with varying diameters and wall thicknesses. (b) Visual appearance of various samples of gold hollow nanospheres. Reprinted with permission from ref. 24. Copyright 2006 American Chemical Society.

From the practical point of view it is important that in the case of spherical silver and gold nanoparticles it is very difficult to shift the position of the SPR band. For example, spherical Ag nanoparticles with diameter of $60 \mathrm{~nm}$ absorb at $c a .400 \mathrm{~nm}$, while $5 \mathrm{~nm}$ nanoparticles have absorption band at $390 \mathrm{~nm} .^{22}$ Analogously, spherical gold nanoparticles with average diameter of $16 \mathrm{~nm}$ exhibit SPR band at $520 \mathrm{~nm}$, when bigger $59 \mathrm{~nm}$ nanoparticles exhibit SPR at $534.5 \mathrm{~nm} .^{23}$

Interesting systems with tunable plasmonic properties are spherical hollow nanoparticles. ${ }^{24}$ For example, for spherical hollow gold nanoparticles it is possible to change the position of the plasmon band by more than $300 \mathrm{~nm}$ by changing the external and internal radiuses. ${ }^{24}$ Analysis of spectra of hollow gold structures showed that increasing of the outer diameter of nanoparticles and keeping constant thickness of the shell causes shift of the SPR band into longer wavelength (red shift). ${ }^{24}$ Increasing the thickness of the shell and keeping constant outer diameter induces shift of the SPR band into shorter wavelength (blue shift) - see Fig. 3. ${ }^{24}$ Also for silver nanoparticles there are significant differences between plasmonic properties of full ("solid") and hollow nanoparticles with the same outer diameter. For example, UV-vis extinction spectrum of sol containing solid spherical silver nanoparticles with the diameter of about $60 \mathrm{~nm}$ reveals strong extinction peak at $400 \mathrm{~nm}$, whereas in the case of spherical hollow nanoparticles (with the ratio of external and internal radiuses equal to 1.55) the plasmon peak is shifted to about $550 \mathrm{~nm} .^{25}$

\section{Distribution of electromagnetic field around anisotropic "plasmonic" systems}

When surface plasmons are excited in metal nanoparticles the intensity of the electromagnetic field at some places may be significantly larger than the intensity of the incident radiation. In the literature there are numerous publications about the distribution of the electromagnetic field around single "plasmonic" nanoparticles with different shape and around agglomerates of two or more "plasmonic" nanoparticles. In the case of an isolated nanoparticle the strongest field enhancement usually occurs on its sharp edges (see Fig. 1b). ${ }^{10,26}$ In the 
case of dimers and other agglomerates very large enhancement is observed when nanoparticles are relative close to each otherthe strongest field is in the slit/slits between nanoparticles (see Fig. 1c) ${ }^{27-29}$ Places with especially high field enhancements are called "hot-spots". ${ }^{30}$ In some cases it is possible to obtain enhancement of the intensity of the electromagnetic field even above $10^{2}$ times. ${ }^{27}$ This property of some nanoparticles (especially $\mathrm{Au}$ or Ag ones) allows to carry out many surface-specific spectroscopic measurements such as: surface-enhanced Raman scattering (SERS), surface-enhanced hyper-Raman scattering (SEHRS), surface-enhanced infrared absorption (SEIRA) or metal-enhanced fluorescence (MEF).

Distribution of electromagnetic field around nanoparticles strongly depends on the nanoparticle shape. As mentioned above the strongest enhancement of the electromagnetic field is usually observed on sharp edges of nanoparticles, however, in some cases, the strongest field enhancement appears in other places. For example, in 2003 Schatz's group analyzed the enhancement of the electric field outside silver nanoprism under various irradiation - see Fig. 1 b. ${ }^{10}$ Simulations have been carried out for $16 \mathrm{~nm}$ thick silver right nanoprism with $100 \mathrm{~nm}$ edges of the bases. Irradiating light was polarized along the bisector of the base of the nanoprism. Schatz found that while irradiating nanoprism using radiation with the wavelength of $770 \mathrm{~nm}$ the highest field enhancement around nanoprism (over 22 times) is observed at the tips of the nanoprism. While irradiating using radiation with the wavelength of $460 \mathrm{~nm}$ the highest enhancement occurs at the middle of triangle's sides opposite to the triangle's edge, but this enhancement is much smaller than the enhancement at tips when using $770 \mathrm{~nm}$ radiation - see Fig. 1b. ${ }^{10}$ This behaviour is due to the possibility of the excitation in nanoprisms of various plasmonic modes. Nanoprisms of all kinds has four plasmon resonance peaks: out-of-plane quadrupole, in-plane quadrupole, in-plane dipole, and weak out-of-plane dipole. When $770 \mathrm{~nm}$ radiation is used for excitation of surface plasmons the distribution of electric field outside the nanoprism is similar to this obtained from dipole excitation in spherical nanoparticles while for excitation with $460 \mathrm{~nm}$ radiation the distribution of the electromagnetic field outside the nanoprism is similar to the distribution of the electromagnetic field due to the quadrupole excitation in spherical nanoparticle. ${ }^{10}$

It is worth to note that the maximum achievable field enhancement factor for anisotropic nanoparticles is significantly larger than for isotropic spherical nanoparticles. For example, the maximum enhancement factor for spherical $\mathrm{Ag}$ nanoparticles (with the diameter of $20 \mathrm{~nm}$ ) irradiated using the light with the wavelength of $700 \mathrm{~nm}$ is calculated to be 14 times the applied field, whereas the maximal field enhancement factors for nanoprisms, nanorods, and nanospheroids irradiated using radiation with the same wavelength are estimated as equal to $59.1,67$, and 68.5 , respectively. ${ }^{27}$

Very interesting plasmonic properties can be observed for dimers and larger agglomerates of metal nanoparticles. For example, for a dimer of spherical nanoparticles irradiated with the light polarized parallel to the interparticle axis two plasmon peaks are observed: one at $520 \mathrm{~nm}$ that is due to a dipole resonance, and the second (weaker) at $430 \mathrm{~nm}$ that is due to a quadrupole resonance. For these systems very large enhancement of the electric field may be also obtained in narrow slits between nanoparticles - even $c a .10^{3}$ for dimers of spherical nanoobjects (see Fig. 1c). ${ }^{31}$ For dimer of triangular nanoprisms positioned on a common plane with tips directed toward each other and irradiated with light polarized parallel to the interparticle axis the theoretically calculated field enhancements are very large even when considering only dipole or only quadrupole resonance. Considering only the dipole resonance the field enhancement was calculated to be equal to $2.3 \times 10^{2}$, whereas considering only the quadrupole resonance the field enhancement was calculated to be equal $75 .{ }^{27}$ Such big enhancement factor for some places between nanoparticles (so called "hot spots") enable, for example, single molecule measurements using SERS spectroscopy. ${ }^{32}$

Because of a large increase of the efficiency of many optical processes occurring for molecules being present in the "hot spots", some groups developed techniques which allow on more efficient trapping of molecules of an analyte in such places. ${ }^{33}$ For example, Kumacheva et al. presented a method for trapping molecules of dyes at the "hot spots" formed between ends of the self-assembled gold nanorods. ${ }^{34}$ First, gold nanorods were modified with thiol-terminated polystyrene and then nanorods were self-assembled in the presence of analyte, which facilitates trapping of molecules of analyte (SERS dyes) at the "hot spots" formed between the ends of the gold nanorods. ${ }^{34}$ Another approach has been applied by Suh et $a l^{35}$ In the first stage they formed dimers from gold nanoparticles surface-modified with DNA (some of DNA were dye-labelled). ${ }^{35}$ In the second stage, the interparticle gap between gold nanoparticles forming dimer was decreased by coating a silver shell on them, which significantly increase efficiency of electromagnetic hot spots between plasmonic metal nanoparticles. ${ }^{35}$

\section{Selected analytical applications of gold and silver nanoparticles}

\subsection{Methods based on measurement of UV-vis spectra}

Plasmonic optical properties of metal nanostructures depend on their geometrical parameters (shape and size) and dielectric properties of the metal and the surroundings (on the presence of other plasmonic object in the close proximity and on the dielectric properties of the environment). The frequency of the plasmon resonance is particularly strongly dependent on the shape of metal nanostructures and on the possible electromagnetic coupling with the localized surface plasmons in nearby other plasmonic objects. Therefore, for sols of plasmonic nanoparticles (like $\mathrm{Ag}$ and $\mathrm{Au}$ ) even small change of the degree of agglomeration may be often easily detected by the observation of the change of their UV-vis spectrum. In some cases aggregation of nanoparticles may cause visible change of the colour of the solution. Very easy detection of agglomeration of the plasmonic nanoparticles induced by some compounds (analytes) resulted in the development of many analytical procedures based on the observation of the change of the 
extinction of the plasmonic sols. For example, Hupp et al. developed analytical method for determination of the concentrations of lead, cadmium, and mercury cations (in the concentration range between $50-200 \mu \mathrm{M}$ ) based on aggregation of gold nanoparticles. ${ }^{36}$ Addition of ions of heavy metals causes change of the colour of the solution from blue to red. Red to blue change in colour of the solution could be reversed by the addition of complexing agent like EDTA. For these measurements gold nanoparticles are functionalized by heavy-metal ion receptor, 11-mercaptoundecanoic acid (MUA). The reversible aggregation of nanoparticles are induced by coordination of cations of heavy atoms by MUA. This leads to decrease of negative charge on the nanoparticle surfaces causing the nanoparticles to repel each other much more weaker. Similar method based on the agglomeration of gold nanoparticles can be effectively used to measure concentrations of lithium ions in the 10-100 $\mathrm{mM}$ range and copper cations in the range 50-500 $\mu \mathrm{M} \cdot{ }^{37,38}$ Obare et al. showed that using smaller nanoparticles for this kind of analysis allows for achieving lower detection limit of the analyte. ${ }^{37}$ An analogous aggregation method has been developed by Fan et al. for detection of platinum ions. ${ }^{39}$ In this case gold nanoparticles have been modified by streptavidin aptamer. Using this method Fan et al. were able to determine colorimetrically concentration of $\mathrm{Pt}(\mathrm{II})$ ions in the range from $0.6 \mu \mathrm{M}$ to $12.5 \mu \mathrm{M} .{ }^{39}$ Silver nanoparticles stabilized by starch can be used for colorimetric detection of copper(II) ions. ${ }^{40}$ This method has low detection limit, high selectivity, and could be used for real environmental water samples. In some cases it is even possible to use unmodified (bare) metal nanoparticles for such colorimetric measurements. For example, Shellaiah et al. observed aggregation of gold nanoparticles after addition of $\mathrm{Cr}^{3+}$ ions, which allows for using bare gold nanoparticles for rapid colorimetric detection of $\mathrm{Cr}^{3+}$ ions in aqueous media. ${ }^{41}$ The detection limit of chromium ions was determined as equal to $c a .13 \mathrm{nM}$ and it was also found that the colorimetric detection of $\mathrm{Cr}^{3+}$ ions may be carried out in the presence of many other metal ions. ${ }^{41}$

Very interesting and novel method for detection of $\mathrm{Hg}^{2+}$ ions has been recently described by Chen et al. ${ }^{42}$ This method is based not on agglomeration of plasmonic nanoparticles but on the change of their plasmonic properties during their growth. Chen et al. added analysed samples containing mercury ions into gold colloids prepared by the standard citrate reduction. ${ }^{42}$ Next, they added hydroxylamine $\left(\mathrm{NH}_{2} \mathrm{OH}\right)$ and chloroauric acid $\left(\mathrm{HAuCl}_{4}\right)$. In this conditions hydroxylamine is able to reduce $\mathrm{HAuCl}_{4}$ into metallic gold. However, mercury ions are also reduced on the surface of gold nanoparticles. Depending on the amount of added mercury ions the growth of nanoparticles can be different. Gold nanoparticles with low mercury cover grow into spherical objects with slow growth rate which results in red-coloured solutions, while gold nanoparticles with high mercury coverage grow very quickly, nanoparticles with larger diameters are formed and colour is changing from red to blue. What is important other cations do not disturb this analysis. The detection limit of this method was estimated as equal to 0.26 nM. $^{42}$
Determination of metal ions may be also based on deaggregation of plasmonic metal nanoparticles. For example, He and Zhang developed sensitive method of colorimetric detection of $\mathrm{Mn}^{2+}$ ions based on de-aggregation of modified silver nanoparticles. ${ }^{43} \mathrm{He}$ and Zhang prepared Ag nanoparticles modified with L-arginine. Addition of L-arginine causes efficient aggregation of $\mathrm{Ag}$ nanoparticles, which leads to fading of the colour of the Ag sol. However, addition of manganese ions can reverse aggregation of arginine-modified silver nanoparticles and induces appearance of intensive yellow colour. Therefore, by the measurement of the absorbance of the solutions at $390 \mathrm{~nm}$ one can determine the amount of manganese ions added (the higher adsorption, the higher concentration of the $\mathrm{Mn}^{2+}$ ions). This colorimetric method allows for determination of $\mathrm{Mn}^{2+}$ ions in the $300 \mathrm{nM}$ to $60 \mu \mathrm{M}$ concentration range. ${ }^{43}$ Moreover, such colorimetric detection of $\mathrm{Mn}^{2+}$ ions exhibits very high selectivity because addition of different metal ions like: $\mathrm{K}^{+}, \mathrm{Ca}^{2+}, \mathrm{Na}^{+}, \mathrm{Mg}^{2+}, \mathrm{Ba}^{2+}, \mathrm{Al}^{3+}, \mathrm{Fe}^{2+}, \mathrm{Fe}^{3+}, \mathrm{Cu}^{2+}, \mathrm{Sr}^{2+}, \mathrm{Cs}^{+}$, $\mathrm{Pb}^{2+}, \mathrm{Ni}^{2+}, \mathrm{Co}^{2+}, \mathrm{Cr}^{3+}$, and $\mathrm{Hg}^{2+}$ does not cause observable deaggregation of arginine-modified silver nanoparticles. ${ }^{\mathbf{4 1}}$ Similar method for detection of manganese ions has been proposed by $\mathrm{Wu}$ et al. $^{\mathbf{4 4}}$ In this case silver nanoparticles have been modified with tripolyphosphate $\left(\mathrm{P}_{3} \mathrm{O}_{10}{ }^{5-}\right)$. Due to high selectivity and good linearity (from $0.05 \mu \mathrm{M}$ to $20 \mu \mathrm{M}$ ) this method can be used for detection of $\mathrm{Mn}^{2+}$ ions in real environmental water samples like lake and tap water. ${ }^{\mathbf{4 4}}$

The other interesting colorimetric method utilising plasmonic nanoparticles is detection based on etching of the existing plasmonic nanoparticles that generates a colour change. For example, Gao et al. and Guo et al. demonstrated the possibility of using of the process of etching of triangular silver nanoprisms for the detection of various compounds. ${ }^{45-47}$ In the simplest approach Guo et al. directly detected the etching agent (hydrogen sulphide) by the analysis of the SPR band of silver nanoparticles - increase in the concentration of hydrogen sulphide (etching agent) results in a decrease in absorbance and red shift of the SPR peak of the silver nanoprisms as they are etched. ${ }^{47}$ Using non direct approach (the actual etching agent was $\mathrm{H}_{2} \mathrm{O}_{2}$, which was produced in a catalytic reaction from the dissolved molecular oxygen) Gao et al. was even able to detect target DNA at concentrations as low as $6.0 \mathrm{fM}^{46}$

In addition to mentioned above colorimetric detection of DNA, methods utilising plasmonic nanoparticles and based on various processes influencing plasmon resonance (usually aggregation of plasmonic nanoparticles or changing of the electric permittivity of the environment) are often used for detection of organic compounds, even such as proteins and nucleic acids. ${ }^{4-52}$ For example, Feng et al. described sensitive method for phosgene detection based on aggregation of gold nanoparticles. ${ }^{52}$ In this case gold nanoparticles are capped by Lcysteine due to the strong affinity of the - $\mathrm{SH}$ group to gold surface. L-Cysteine molecule is attached to the gold surface via $\mathrm{S}-\mathrm{Au}$ bond. Gold nanoparticles exhibit strong absorption peak at $520 \mathrm{~nm}$, but after addition of phosgene their colour changes from wine-red to purple-blue (see Fig. 4).$^{52}$ It is caused by the formation of new absorption peak at $640 \mathrm{~nm}$, which is ascribed to the agglomerates of gold nanoparticles (see Fig. 4). ${ }^{52}$ 
a)

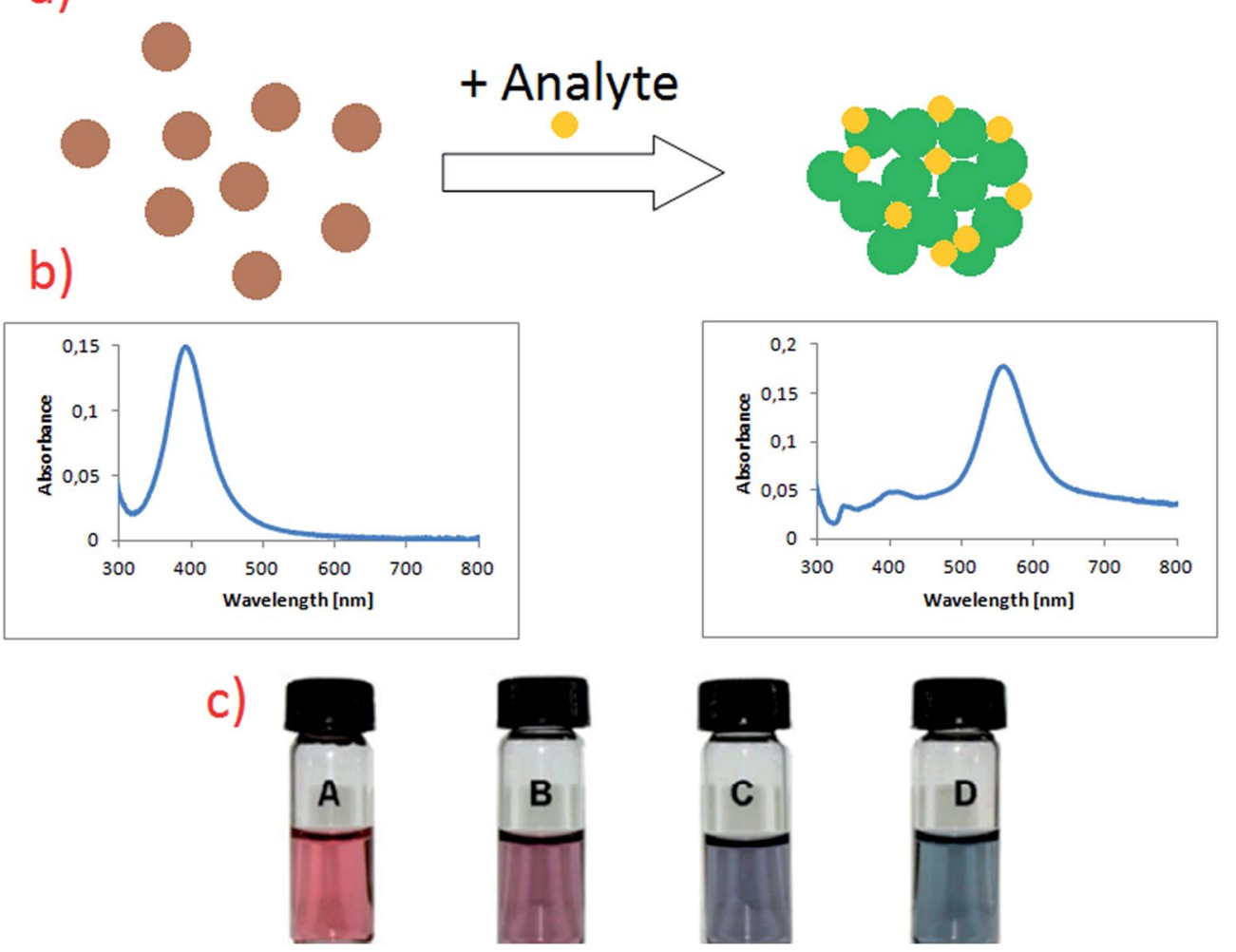

Fig. 4 (a) Schematic illustration showing the change in noble metal nanoparticles solutions after addition of analyte. (b) Respectively UV-vis spectra of sol of noble metal nanoparticles before and after addition of analyte. (c) Colour change in L-cysteine modified gold nanoparticles after exposure to different concentrations of phosgene in air: (A) 0, (B) 1.4, (C) 1.9, (D) $2.5 \mathrm{mg} \mathrm{ml}^{-1}$. Reprinted with permission from ref. 52 . Copyright 2010 The Royal Society of Chemistry.

Additionally, non-modified gold nanoparticles have been also tested for phosgene detection. Modified and non-modified gold nanoparticles exhibits strong absorption peak at $520 \mathrm{~nm}$, which shows that cysteine molecule hardly affects the spectroscopic properties of Au nanoparticles. Subsequent addition of phosgene in a case of non-modified nanoparticles did not cause any obvious colour change. It means that the detection of phosgene molecules is only possible due to the modification of the surface of gold nanoparticles by chemisorbed cysteine. This method provides a linear response in the concentration range of phosgene between 5 and $50 \mu \mathrm{M} .^{52}$

Interesting aggregation technique has been also applied by Guo et al. for the detection of target DNA (see Fig. 5). ${ }^{47}$ In this strategy, unlike the conventional colorimetric methods based on formation of large nanoparticle aggregates, dimers of plasmonic nanoparticles are selectively formed upon target binding, which results in significantly improved long-term stability and a more than 2 orders of magnitude wider dynamic range of detection than that of the conventional colorimetric sensors. ${ }^{47}$ Moreover, significant decreasing of the interparticle gap through the formation of a Y-shaped DNA duplex (see Fig. 5) enables to increase the limit of detection by $10^{4}$ times. $^{47}$

Plasmonic sensors for detection of various species may also utilise the influence on the plasmon resonance of the electric permittivity of the environment of the plasmonic structures. For example, Ding et al. fabricated a triangular silver nanoparticle array, to which protein p53 antibody has been chemically attached. ${ }^{53}$ Then, such modified nanoparticle arrays have been incubated with various serums containing protein p53. ${ }^{53} \mathrm{In}$

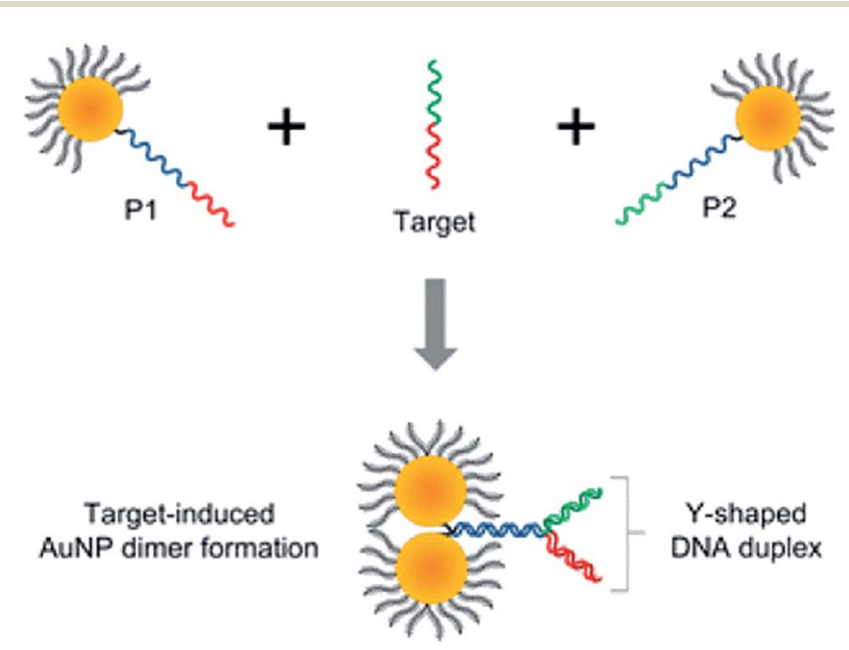

Fig. 5 Schematic representation of the formation of nanoparticle dimers upon target DNA binding using the asymmetrically modified gold nanoparticles. Reprinted with permission from ref. 47. Copyright 2013 American Chemical Society. 


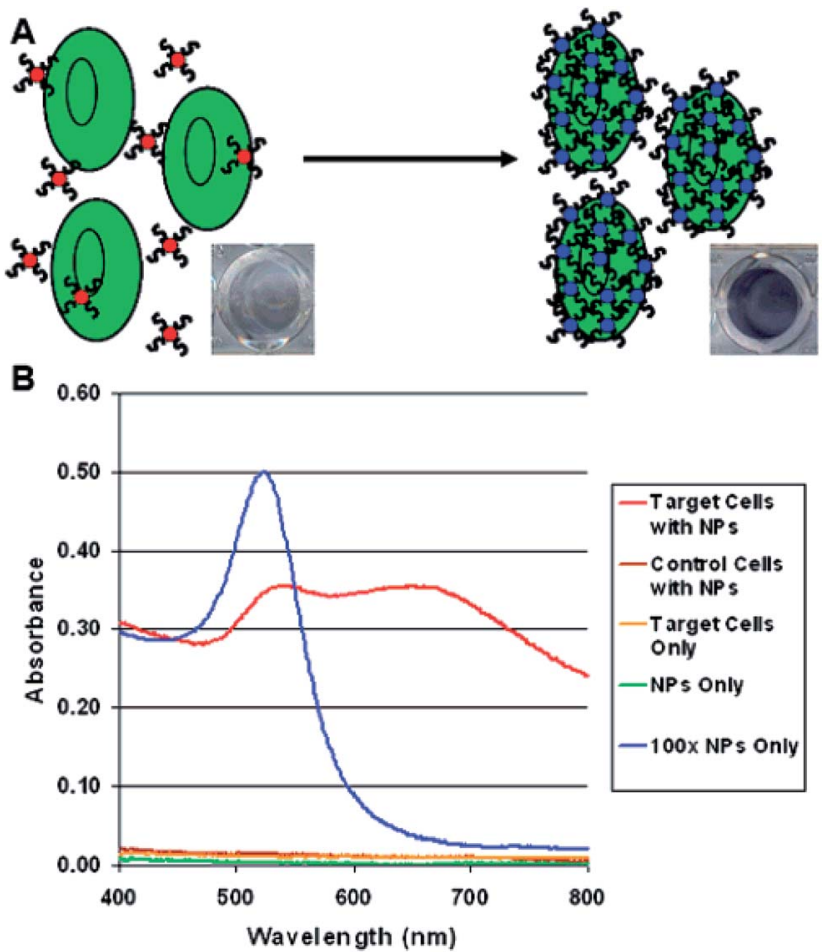

Fig. 6 (A) Schematic representation of the colorimetric detection of cancer cells using aptamer-conjugated gold nanoparticles. (B) Plots depicting the absorption spectra obtained for various samples analyzed using aptamer-conjugated gold nanoparticles. The spectra illustrate the differences in the spectral characteristics observed after the aptamer-conjugated gold nanoparticles bind to the target cells. Reprinted with permission from ref. 54. Copyright 2008 American Chemical Society.

healthy humans the level of protein p53 is $c a .16 \mathrm{pg} \mathrm{ml}^{-1}$ whereas in a case of patients with some cancers diseases concentration of p53 is elevated to $c a .60 \mathrm{pg} \mathrm{m}^{-1}$. Ding et al. found that difference in the position of the plasmon peak (due to the adsorption of the molecules of analyte on the plasmonic structures) for sensor soaked in serum from a patient and a control serum is equal to $c a .18 \mathrm{~nm}$, which is significantly larger than differences observed for the control group $(<5 \mathrm{~nm}) .^{53}$

Colorimetric methods may be also applied for detection of larger bio-objects, such as cancer cells (see Fig. 6)..$^{54}$ This method relies on aptamer-conjugated gold nanoparticles. Aptamers are oligonucleotide strands that bind to their targets with high affinity and selectivity. For example, Medley et al. conjugated aptamer sequences to $20 \mathrm{~nm}$ gold nanoparticles via thiol functional groups. ${ }^{54}$ In this experiment five samples with different concentration of nanoparticles with target and control cells was prepared. Absorbance (especially at $c a .680 \mathrm{~nm}$ ) of Au nanoparticles with target cells (due to their agglomeration) is significantly higher than in the case of the same amount of nanoparticles with control cells (see Fig. 6). These results show that Au nanoparticles are binding selectively to the target cells which causes increase in the absorption and scattering of the solution (see Fig. 6)..$^{54}$

\subsection{Surface-enhanced Raman scattering}

As mentioned in the Introduction the local enhancement of the intensity of the electromagnetic field in the proximity of plasmonic nanoparticles may cause significant increase of the efficiency of several optical processes, which are commonly applied in the chemical analysis, such as fluorescence, infrared absorption, and Raman scattering (which includes also Raman optical activity, hyper-Raman scattering and coherent antiStokes Raman scattering). From the practical point of view the most important application of plasmonic nanoparticles is increasing of the efficiency of Raman scattering, and therefore, we will start characterization of spectroscopic methods utilizing metal nanoresonators from description of the applications of plasmonic nanoparticles in this field of spectroscopy.

Raman scattering relies on an inelastic photon scattering. In contrast to elastic Rayleigh scattering, inelastically scattered photons have different energy from the incident ones. For many years Raman spectroscopy has not been considered a useful analytical tool because of very low efficiency of the "normal" Raman scattering. Typical total Raman scattering cross-section is only $c a \cdot 10^{-29} \mathrm{~cm}^{2}$ per molecule, whereas typical crosssections for absorption in ultraviolet and infrared are $c a$. $10^{-18}$ and $10^{-21} \mathrm{~cm}^{2}$ per molecule, respectively. ${ }^{55}$ In 1974 Fleischmann et al. reported a significant growth of the Raman signal measured from pyridine adsorbed on electrochemically roughened (nanostructured) silver substrate. ${ }^{56}$ They interpreted this effect as a result of an increase of the surface area of electrochemically roughened silver electrode and hence adsorption of a significantly larger number of pyridine molecules. Three years later two independent research groups found true reasons for the very large growth of the intensity of the Raman signal observed by Fleischmann et al. ${ }^{56}$ Jeanmaire and van Duyne, and Albrecht and Creighton connected very strong Raman signal observed for pyridine adsorbed on nanostructured $\mathrm{Ag}$ surface with the increase of the efficiency of Raman scattering..$^{57,58}$ The observed effect was called SERS (surface-enhanced Raman scattering). As mentioned above, the increase of the efficiency of Raman scattering for molecules being in the close proximity to the plasmonic nanoparticles is mainly due to the increase of the intensity of the electromagnetic field. Kerker et al. found that for molecules at the surface of metallic spheres the electromagnetic SERS enhancement (EF) can be calculated from the following simple expression: ${ }^{59}$

$$
\mathrm{EF}=5 \times\left|\left(1+2 \times g_{\mathrm{d}}\left(\omega_{\mathrm{o}}\right)\right) \times\left(1+2 \times g_{\mathrm{d}}(\omega)\right)\right|^{2}
$$

where:

$$
g_{\mathrm{d}}(\omega)=\frac{\epsilon_{\mathrm{i}}(\omega)-\epsilon_{\mathrm{o}}(\omega)}{\epsilon_{\mathrm{i}}(\omega)+2 \epsilon_{\mathrm{o}}(\omega)}
$$

$\omega_{\mathrm{o}}$ and $\omega$ are the wavenumbers of the incident and Raman radiations, respectively, $\epsilon_{\mathrm{i}}$ is the electric permittivity of the metal and $\epsilon_{\mathrm{o}}$ is the electric permittivity of nanoparticle's environment. It can be shown that for Raman bands with small socalled Raman shift (it means difference between $\omega_{\mathrm{o}}$ and $\omega$ ) EF is roughly proportional to the fourth power of the field enhancement. ${ }^{55,60-62}$ 

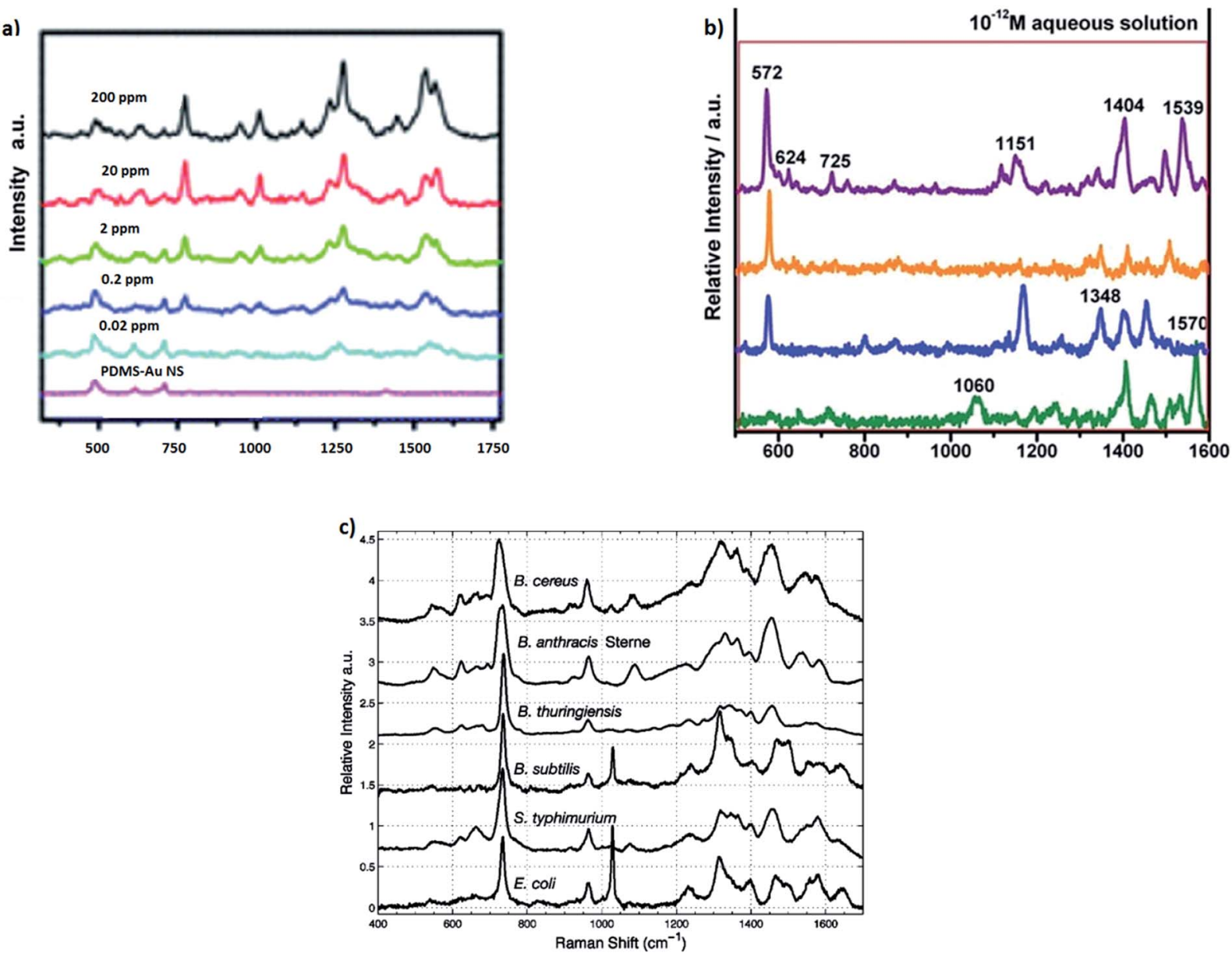

Fig. 7 (a) SERS spectra of the different concentrations of thiabendazole deposited on apple fruit skin with gold nanostars used as optical nanoresonators. Reprinted with permission from ref. 82. Copyright 2014 Royal Society of Chemistry. (b) Single molecule SERS spectra of adenine measured from the solution with the concentration of $10^{-12} \mathrm{M}$. Reprinted with permission from ref. 69 . Copyright 2014 Royal Society of Chemistry. (c) SERS spectra of different Gram-positive and Gram-negative bacteria. Reprinted with permission from ref. 87. Copyright 2005 American Chemical Society.

In addition to the increase of the efficiency of Raman scattering due to the local enhancement of the intensity of the electromagnetic field, the enhancement of the Raman signal for molecules adsorbed on metal nanoclusters is also due to the socalled charge transfer mechanism that resembles the ordinary resonance Raman process. The largest enhancement in socalled charge transfer mechanism is observed when the energy of photons in the incident beam is fitted to the difference between energies of Fermi level in the metal and an unoccupied molecular orbital of absorbed molecule or between the highest occupied molecular orbital of absorbed molecule and Fermi level in metal. By the modification of the potential in the electrochemical systems it is possible to control the energy of Fermi level in metal, and hence to influence the value of the enhancement due to the charge transfer mechanism. ${ }^{63-65}$

Utilising both SERS and resonance Raman effects, the Raman scattering cross-section can be sometimes increased even to $2 \times 10^{-14} \mathrm{~cm}^{2}$ per molecule (i.e. by about 15 orders of magnitude in comparison to the cross-section of normal Raman scattering) making possible observation of SERS spectra even of a single molecule. ${ }^{66-68}$ Although, as far as we known, single molecule SERS spectroscopy has not been used for practical analysis due to the poor reproducibility of the measured signal (for example see Fig. 7, which shows single molecule SERS spectra of adenine measured from the solution with the concentration of $\left.10^{-12} \mathrm{M}\right){ }^{69}$ its strong fluctuation and possibility of the complete disappearance of the signal due to the photodecomposition of the investigated molecule, SERS is actually one of the most sensitive analytical tools with the limit of detection for some analytes of the order of $10^{-18} \mathrm{~mol} \mathrm{dm}{ }^{-3} .^{70}$ The other problem connected with very strong local enhancement of the intensity of the electromagnetic field in so-called "hot spots" is appearing in the measured SERS spectra of a background from "carbon impurities" (carbon clusters are produced by the photocatalytic decomposition of various organic compounds in SERS "hot spots"). The more detailed analysis of this problem may be found in ref. 71 and 72.

The simplest SERS analytical procedures are based on the measurement of the SERS signal of the analyte. For example, some anthraquinone dyes can be detected by recording of the 
SERS spectrum from highly SERS-active substrate immersed in the analysed solution (SERS substrate can be prepared, for example, by evaporating a layer of silver nanoparticles on the surface of $\mathrm{Al}_{2} \mathrm{O}_{3}$ or by deposition of a layer of silver nanoparticles directly on pieces of the filter paper). The limit of detection of alizarin (one of the studied dyes) using this simple SERS measurement was estimated to be $7 \times 10^{-15}$ g. ${ }^{73}$ In 2015 Lian et al. synthesised very efficient SERS substrates by deposition of $\mathrm{Au}$ nanoparticles on $\mathrm{MoO}_{3}$ nanowires. ${ }^{74}$ Using such SERS substrates Lian et al. were able to detect melamine in the solution with the concentration of $0.08 \mathrm{nM}(0.1 \mathrm{ppb}) .^{74}$

Solid samples may be analysed using SERS spectroscopy by covering of their surfaces by the plasmonic metal nanoparticles (electromagnetic nanoresonators) and subsequent recording of the Raman spectra. Such approach has been applied, for example, to detect dyes in textiles. ${ }^{75}$ Using silver nanoresonators Leona et al. analysed fibre from a sixteenth-century Dutch tapestry. In the recorded Raman spectra of such sample Leona et al. identified bands characteristic to alizarine, and hence, proved the presence of this dye in the analysed sample. ${ }^{75}$ Recorded SERS spectra are very characteristic of scattering molecules, and therefore this technique is recommended for atypical samples, for which unexpected compounds present in the sample could seriously interfere with the result of the analysis carried out with many standard analytical methods, e.g., electrochemical analytical techniques or UV-vis absorption spectroscopy.

In some cases plasmonic metal nanoparticles for surface Raman measurements are covered by ultrathin layer of $\mathrm{SiO}_{2}$, $\mathrm{MnO}_{2}$ or $\mathrm{Al}_{2} \mathrm{O}_{3}$ separating metal nanoparticles from direct contact with the probed material and keeping them from agglomerating. ${ }^{25,76-80}$ This Raman technique for surface analysis is called SHINERS (shell-isolated nanoparticle-enhanced
Raman spectroscopy). ${ }^{2,76-80}$ Oxide layers do not exhibit plasmonic properties, however, if they are very thin and used material is transparent, they have not damped significantly surface electromagnetic enhancement (see Fig. 8). Fig. 8a and b shows transmission electron microscopy (TEM) micrographs of example nanoresonators used for SHINERS measurement (solid and hollow silver nanoparticles covered by a $\mathrm{SiO}_{2}$ layer).

Fig. 8c shows an example result of SHINERS analysis: detection of traces of methyl parathion (which is an efficient insecticide) on the surface of an orange fruit. As can be seen in Fig. 8c there are no significant differences between Raman spectra recorded from the surface of the clean orange fruit and the surface of the orange fruit contaminated with methyl parathion. ${ }^{80}$ However, when SHINERS nanoresonators are deposited on the surface of the orange fruit contaminated with methyl parathion, the Raman band due to methyl parathion at $1350 \mathrm{~cm}^{-1}$ (marked with asterisk in Fig. 8c) can be clearly noticed in the measured spectra. ${ }^{80}$

Interesting SERS method useful also for detection of traces of pesticides on the surface of fruits has been recently developed by Singh et al. ${ }^{81}$ This group has synthesized large area flexible SERS substrates by embedding $\mathrm{Ag}$ nanorods into the polydimethylsiloxane polymer. These flexible SERS substrates may be used, for example, for direct extracting of trace amount $\left(\sim 10^{-9} \mathrm{~g} \mathrm{~cm}^{-2}\right)$ of thiram pesticide directly from fruit peels via simple "paste and peel off" method. The SERS detection of thiram pesticide is based on measurement of the intensity of the Raman band at $1386 \mathrm{~cm}^{-1}$, which is due to the vibration of methyl group in thiram molecule. This analytical method allows for detection of surface concentrations of thiram even 3 orders of magnitude lower than the level currently permissible in farming. ${ }^{81}$ In another study Liz-Marzan et al. showed utilization of gold nanostars (efficient plasmonic nanoparticles) for SERS
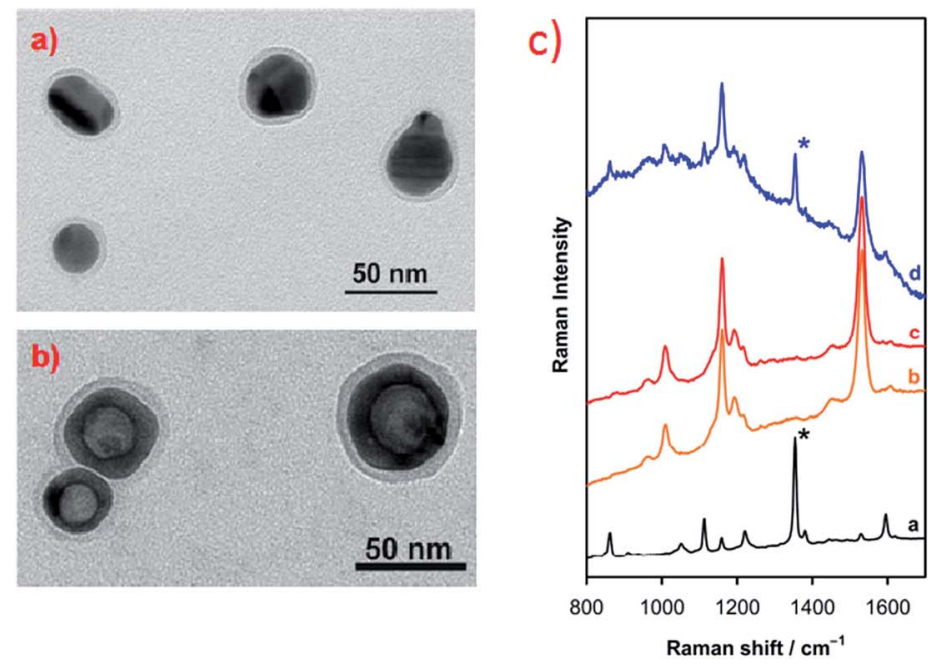

d)

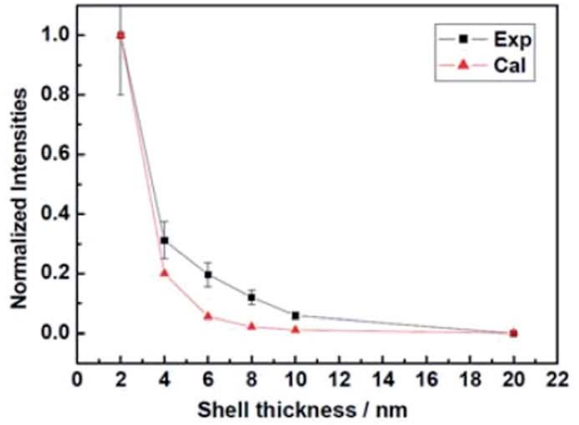

Fig. 8 (a) and (b) TEM micrographs of example nanoresonators for SHINERS measurement: (a) Ag@SiO ${ }_{2}$ nanoparticles, (b) hollow-Ag@SiO 2 nanoparticles. Reprinted with permission from ref. 25. Copyright 2015 American Chemical Society. (c) Raman spectra of: [a] methyl parathion, [b] skin of the orange fruit, [c] skin of the orange fruit contaminated by methyl parathion, [d] skin of the orange fruit contaminated by methyl parathion and covered with $\mathrm{Ag}\left(\mathrm{MnO}_{2}\right.$ nanoparticles. Reprinted from ref. 80 with permission from Elsevier. Copyright 2016 Elsevier. (d) Experimental and theoretical calculations of the influence of the width of silica layer deposited on nanoresonators on the intensity of Raman signal. Reprinted with permission from ref. 76. Copyright 2010 Nature Publishing Group. 
detection of thiabendazole pesticide on the surface of apple skin. ${ }^{82}$ As can be seen in Fig. 7a, Liz-Marzan et al. were able to obtain very small detection limit of thiabendazole $(0.02 \mathrm{ppm}) .{ }^{82}$

SERS spectroscopy may be also applied for detection of relatively complex biological agents, such as viruses, fungi, bacteria, and bacterial spores. Rapid and reliable detection of some of these bioagents is very important in order to detect a terrorist attack with biological warfare. Detection of spores of Bacillus anthracis, which are dangerous pathogens for the disease anthrax, is particularly important from the practical point of view. The procedures of detection of this pathogen utilizing SERS spectroscopy have been developed by several groups. ${ }^{\mathbf{8 3 - 8 6}}$ The SERS detection of Bacillus anthracis spores is usually based on the detection of calcium dipicolinate, which exists in large quantity (about $10 \%$ of the spore's dry weight) in the protective layer of the spore. ${ }^{\mathbf{8 6 , 8 7}}$

Covering the surface of many microorganisms (bacteria, viruses) with plasmonic metal nanoparticles allows for measurements of so-called whole-organism SERS spectra. Due to the specific enhancement mechanism, the recorded SERS spectra are dominated by the contribution from compounds that are near the surface of the metal clusters which means that they are in the outermost parts of the microorganisms (the cell wall of a bacterium or the shell of a virus). Since bacterial cell walls differ more between various species than the composition of the bacteria's bulk, SERS spectra of bacteria exhibit usually greater differentiation for various species than their standard Raman spectra. ${ }^{\mathbf{8 7 , 8 8}}$ Some examples of identification of various bacteria based on their SERS spectra can be found in ref. 87-95. For example, Premasiri et al. used SERS spectroscopy to study cell walls of Gram-positive and Gram-negative bacteria. ${ }^{87}$ This method enabled to distinguish both bacterial species and strains from SERS spectra of their nanoparticle-covered cell walls (see Fig. 7c). ${ }^{87}$ It means that in some cases SERS can be considered as a label-free whole-organism fingerprinting technique.
SERS spectroscopy may be also used for detection of some enzymes. Such analysis is usually based on SERS detection of products of the enzyme-catalyzed reactions. For example, Ruan et al. proposed detection of enzyme alkaline phosphatase by the detection of indigo dye produced in the catalytic reaction from 5-bromo-4-chloro-3-indolyl. ${ }^{96}$ The detection limit of alkaline phosphatase using this method was estimated as equal to $10^{-15}$ M. $^{96}$

Important analytical application of SERS spectroscopy is measurement of $\mathrm{pH}$ using $\mathrm{pH}$ nanosensors. Typical SERS $\mathrm{pH}$ sensors are composed of plasmonic metallic nanostructures with molecules of so-called Raman reporters (molecules that significantly change their SERS spectrum with the change of the $\mathrm{pH}$ of the surrounding solution) immobilised on their surfaces. Due to their nanoscale size, such sensors can be successfully introduced into cells of living organisms and track the distribution of the $\mathrm{pH}$ inside the cell. In the interior of the eukaryotic cell there are various structures (organelles) having different functions. Therefore, the distribution of the concentration of $\mathrm{H}^{+}$ ions is not homogeneous, and hence, measurements of local $\mathrm{pH}$ at various places in the interior of the living cell is important. Interesting $\mathrm{pH}$ sensor was developed by Huser et al. ${ }^{97}$ As a molecule sensitive to changes in $\mathrm{pH}$ 4-mercaptobenzoic acid was used. Binding of these molecules to the surface of gold/ silver nanoparticles is realized via their thiol groups. The determination of $\mathrm{pH}$ is realized by the measurement of the relative intensity of the SERS band at $1430 \mathrm{~cm}^{-1}$ due to the vibration of the carboxyl group. As one can expect the relative intensity of this band (calculated versus the intensity of the band at $1590 \mathrm{~cm}^{-1}$ due to the vibration of the aromatic ring) increases with increasing of $\mathrm{pH}$. Kneipp and co-workers introduced this $\mathrm{pH}$ sensor to the live fibroblast NIH/3T3 cell. ${ }^{98}$ As a result, they obtained a map of the distribution of $\mathrm{H}^{+}$ions in the living cell (see Fig. 9). ${ }^{98}$ SERS pH nanosensors may be also based on other Raman reporters such as 4-aminothiophenol or 4-ethynylpyridine..$^{99,100}$

(a)

(b)

(c)

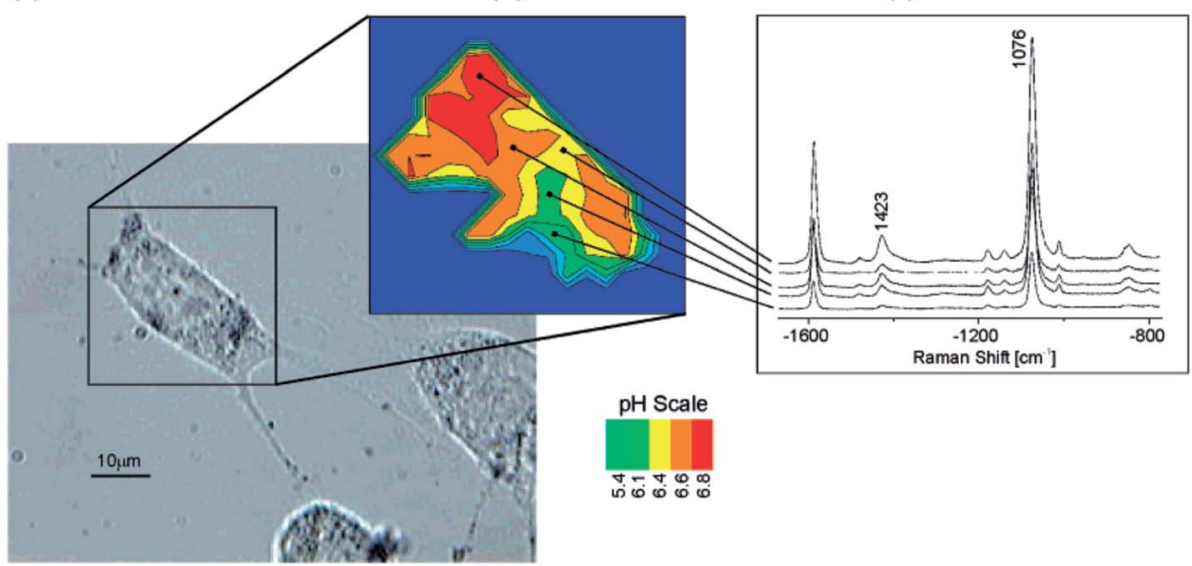

Fig. 9 Probing and imaging $\mathrm{pH}$ values in individual live cells using a SERS nanosensor. (a) Photomicrograph of an NIH/3T3 cell after incubation with gold nanoparticles functionalized with 4-mercaptobenzoic acid. (b) $\mathrm{pH}$ map of the cell displayed as false colour plot of the ratios of the intensity of SERS bands at 1423 and $1076 \mathrm{~cm}^{-1}$. (c) Typical SERS spectra collected in the endosomal compartments with different pH. Reprinted with permission from ref. 98. Copyright 2007 American Chemical Society. 
Similar SERS nanosensors could be also used for detection of other cations. For example, Piotrowski and Bukowska showed that silver nanoparticles covered by the monolayer of mercaptoethanesulfonate can serve as a sensor for many metal cations. ${ }^{\mathbf{1 0 1}}$ Sulfonate groups of mercaptoethanesulfonate may form contact-ion pairs with metal cations, and therefore $\nu_{\mathrm{s}}\left(\mathrm{SO}_{3}{ }^{-}\right)$band can be split into two components, one at a higher wavenumber $\left(1065 \mathrm{~cm}^{-1}\right)$ for sulfonic groups interacting directly with co-adsorbed cations and one at a lower wavenumber $\left(1040 \mathrm{~cm}^{-1}\right)$ for sulfonic groups which are not involved in the formation of direct bonds with co-adsorbed cations. Piotrowski and Bukowska demonstrated a big potential of such functionalized $\mathrm{Ag}$ nanoparticles for detection of a great variety of cations, including alkaline and alkaline earth metal cations, down to $10^{-8} \mathrm{M}$ in the case of $\mathrm{Ca}^{2+} \cdot{ }^{101}$ SERS sensor developed by Chen et al. for detection of $\mathrm{As}^{3+}$ cations utilises other mechanism. In this case addition of $\mathrm{As}^{3+}$ cations induces aggregation of glutathione-modified silver nanoparticles which results in increase of the intensity of the measured SERS spectra. ${ }^{\mathbf{1 0 2}}$ Aggregation of glutathione-modified silver nanoparticles is due to the high affinity of glutathione to $\mathrm{As}^{3+}$ ions, each $\mathrm{As}^{3+}$ ion could bind by the As-O bond to three glutathione molecules (also attached to different $\mathrm{Ag}$ nanoparticles) and hence O-As-O bridges can bond various silver nanoparticles. ${ }^{102}$ This SERS $\mathrm{As}^{3+}$ sensor has good linear response in a wide concentration range (4-300 ppb), low detection limit (0.76 ppb), and has high selectivity - practically only $\mathrm{As}^{3+}$ ions could induce the aggregation of glutathione-modified silver nanoparticles. ${ }^{\mathbf{1 0 2}}$ Similar aggregation-based SERS sensor has been also developed for detection of cadmium ions by Dasary et al. ${ }^{103}$ In this case $\mathrm{Cd}^{2+}$ induces aggregation of alizarin-modified gold nanoparticles (alizarin is a very efficient Raman scatterer) which were further modified with 3-mercaptopropionic acid and 2,6-pyridinedicarboxylic acid. ${ }^{103}$ As in the previous case, aggregation of nanoparticles significantly increases the intensity of measured SERS signal of alizarin (Raman reporter). ${ }^{103}$ Such SERS sensor could detect traces of $\mathrm{Cd}^{2+}$ ions even at $10 \mathrm{ppt}$ level. ${ }^{103}$

Very promising plasmonic method which may be used for chemical analysis is surface enhanced Raman optical activity (SEROA). Raman optical activity (ROA) is a phenomenon of differential scattering of right and left circularly polarized light by chiral molecules (ROA is also manifested as a small circularly polarized component in the scattered light when the incident radiation is linearly polarized). Standard ROA spectrum is very weak, usually 3-5 orders of magnitude weaker than those of the parent Raman scattering. ${ }^{\mathbf{1 0 4}}$ Therefore, increasing of the intensity of the ROA signal by the utilising of metal nanoresonators have been tried by many groups. Since ROA and SEROA spectra collected for $\mathrm{L}^{-}$and $\mathrm{D}$-enantiomers are almost mirror images of each other (when at a given frequency the D-isomer exhibits positive peak the L-form should exhibit negative peak) those analytical techniques allow for distinction of various isomers.

One of the first reports about measurement of the SEROA spectra were published by Kneipp et al. ${ }^{\mathbf{1 0 5}}$ They recorded SEROA spectra of adenine (with the concentration of $8 \times 10^{-5} \mathrm{M}$ ) adsorbed on silver colloid. This report states that using SEROA method allows for considerably shortening data collection time and decreasing concentration of the target molecules. ${ }^{\mathbf{1 0 5}}$ In 2010 Osinska et al. measured SEROA spectra for L- and D-cysteine and proved for the first time that SEROA spectra for L- and D-enantiomers are actually mirror images of each other. ${ }^{106}$ In 2011 Pour et al. showed similar effect for SEROA spectra of $\mathrm{D}^{-}$and L-ribose adsorbed on silver nanoparticles. ${ }^{107}$ SEROA spectroscopy is still not fully understood, however, as mentioned above, this is a potentially sensitive method for detection of chiral molecule like amino acids, nucleotides, proteins or chiral drugs molecules.

\subsection{Surface-enhanced infrared absorption}

Surface enhanced infrared absorption (SEIRA) was described for the first time by Hartstein et al. in $1980 .^{108}$ They found a significant enhancement of the absorption signal of an organic film covered by gold or silver nanoparticles on top. In the next contribution Hartstein reported SEIRA measurement in a configuration when the organic sample was placed as a thin film over the metal surface. ${ }^{\mathbf{1 0 8}}$ In SEIRA measurements it is possible to obtain enhancement factor even equal to $10^{4}$ (in comparison to the standard IR absorption measurements). Such large SEIRA enhancement factor is due to the combination of the electric field enhancement at the metal surface and the specific chemical interactions. A particularly important interaction is a charge transfer between analyte molecule and the metal surface, which leads to enhanced vibrational polarizability of the molecules adsorbed directly onto the metal surface. ${ }^{109}$

In IR absorption spectroscopy intensities of the vibrational modes are proportional to the square of the $E \times \mu^{\prime}$, where $E$ is the electromagnetic field and $\mu^{\prime}$ is the transition dipole moment oriented vertically to the electromagnetic field. ${ }^{\mathbf{1 1 0}}$ In SEIRA phenomenon electromagnetic field that interacts with the molecule is much stronger than the field of the incident IR beam, and as one can deduct from the mentioned above dependence the increase of the efficiency of absorption is proportional the second power of the field enhancement (in SERS experiments the increase of the intensity of measured signal is proportional to the forth power of the field enhancement). Same as in SERS measurements the field enhancement is caused by the surface plasmon resonance taking place on the metal surface (oscillating electrons create additional electromagnetic field).

The orientation of adsorbed molecules versus the metal surface plays an important role in SEIRA spectroscopy. The strongest SEIRA absorption is observed when the transition dipole moment of an adsorbed molecule is oriented vertically with the electric field vector around the metal surface. Such orientation of molecules causes much stronger IR absorption then when molecules are arranged in a chaotic manner (e.g. during physisorption or when they are in solution). It also means that the strongest SEIRA spectra are recorded for ordered monolayers formed by chemisorbed molecules.

SEIRA spectroscopy is mainly used in electrochemical measurements. For example, SEIRA measurements help to understand the mechanism of some electrocatalytic reactions, 
the mechanism of some processes of metal corrosion, to determine the orientation of adsorbed molecules and the structure of formed monolayers. ${ }^{111-114}$

SEIRA spectroscopy is also successfully used in chemical analysis. In some cases this kind of spectroscopy provides fast and repetitive measurement with low-level of the detection. ${ }^{\mathbf{1 1 5 , 1 1 6}}$ For example, Nishikawa et al. reported SEIRA analysis of samples containing nanograms quantity of triphenyl phosphate. ${ }^{115}$ A useful SEIRA spectrum could be obtained even when the amount of deposited analyte is only equal to ca. $25 \mathrm{ng}$ $\mathrm{cm}^{-2}{ }^{115}$ Prati et al. analysed extract from dyed fibers and after mixing with aliquot of gold nanoparticles colloidal solution obtained by laser ablation they were able to detect acid orange on the basis of the measured SEIRS spectra. ${ }^{117,118}$

In biomedical applications surface enhanced infrared absorption spectroscopy can be used for example for detection of rat tumour cells. ${ }^{119}$ This method is based on measurement of the SEIRA spectra of nucleic acids on gold substrate. SEIRA spectra showed that secondary and tertiary structures of nucleic acids from cancer cells are significantly different than structure of nucleic acids from normal cells. ${ }^{\mathbf{1 2 0}}$ Thus, pathologically changed cells have significantly different IR spectra than healthy (cancer-free) cells. DNA from non-pathological cells can be described as rigid structure, when structure of DNA from cancer cells seems to be flexible. As mentioned above this change in DNA structure can be monitored by SEIRA spectroscopy. Detection of the difference between the healthy and cancer cells may be also based on the analysis of SEIRA spectra of RNA. Moreover, the SEIRA spectra of RNA from tumor cells are more sensitive to the grade of tumor malignancy than the SEIRA spectra of DNA. ${ }^{119}$

It is also possible using SEIRA spectroscopy to carry out analysis based on antibody-antigen interactions and molecular and protein recognition. ${ }^{\mathbf{1 2 1 , 1 2 2}}$ For example, in order to prepare SEIRA sensor for Salmonella cell Salmonella antibodies (antiSAL) were immobilized onto a thin gold layer. ${ }^{121}$ SEIRA spectra of anti-SAL sensor with and without deposited cells of Salmonella are significantly different. SEIRA spectrum of anti-SAL deposited on gold layer exhibits two peaks at $1085 \mathrm{~cm}^{-1}$ and $990 \mathrm{~cm}^{-1}$, while in the presence of Salmonella bacteria the measured spectrum exhibits new strong band at $1045 \mathrm{~cm}^{-1}{ }^{121}$ This new band is connected with $\mathrm{P}=\mathrm{O}$ stretching vibration of phospholipids in the bacteria cell wall. Presence of this band can be a clear indication of the presence of Salmonella cell in the solution. Hunter-Cevera et al. showed possibility of detection of different Gram-negative bacteria cells: Pseudomonas putida and Pseudomonas fluorescens by SEIRA measurements on the goldcoated surface of vesicular basalt. ${ }^{123}$ They described three characteristic regions in SEIRA spectra: at $c a .1740 \mathrm{~cm}^{-1}$ connected with phospholipids in the outer membrane of Gramnegative bacteria, $1650 \mathrm{~cm}^{-1}$ due to the bacterial protein amide I envelope and $1550 \mathrm{~cm}^{-1}$ connected with bacterial protein amide II envelope.

Interesting nanoresonators for SEIRA measurements $\left(\mathrm{Fe}_{3} \mathrm{O}_{4} /\right.$ $\mathrm{Au}$ nanocomposites) have been recently developed by Cai et al. ${ }^{124}$ Under strong magnetic field, the superparamagnetic $\mathrm{Fe}_{3} \mathrm{O}_{4} / \mathrm{Au}$ nanoparticles are highly concentrated, leading to the increase number of SEIRA "active sites" between Au nanoparticles and increase of the SEIRA enhancement factor even by one order of magnitude.

\subsection{Metal-enhanced fluorescence}

Fluorescence relies on emission of light by excited molecules. When a molecule in a ground singlet state $\left(\mathrm{S}_{0}\right)$ absorbs a photon, the molecule goes to higher singlet $\left(\mathrm{S}_{1}\right)$ quantum state. The excited molecule can relax to its ground state by two competing pathways: radiative and non-radiative. In a case of radiative relaxation there are two possibilities: transition from $S_{1}$ to $S_{0}$ (without changing multiplicity), which is called fluorescence. The second possibility is intersystem crossing (nonradiative process at this stage) from excited $S_{1}$ state to $T_{1}$ state (triplet excited state). Then molecule can come back to the ground state with emission of light. Transition with changing the multiplicity is prohibited, and therefore phosphorescence can last significantly longer than fluorescence.

Noble metal nanoparticles can also enhance fluorescence. ${ }^{125}$ As in the case of other surface-enhanced spectroscopes surface plasmons excited in nanoparticles are responsible for this effect. Increase of the local electromagnetic field can accelerate both excitation and emission, and can also decrease the lifetime of the excited state. This phenomenon is called metal-enhanced fluorescence (MEF) and allows to increase the limit of detection and sensitivity in some analytical methods based on fluorescence spectroscopy. As mentioned above MEF has two main reasons. ${ }^{126}$ The first contribution is due to the enhancement of the electromagnetic field around nanoresonators. When analysed molecule is in the place when strong enhancement of the electromagnetic field occurs this leads to a significant increase of its absorption cross section which, as a result, enhances fluorescence. The second effect is due to the interactions between excited state of the molecule and surface plasmons. This interaction is responsible for the reduction of the lifetime of the excited state and also increases the quantum yield of fluorescence.

For the molecule of a fluorophore in solution, the quantum yield $(\Phi)$ and lifetime $(\tau)$ can be expressed as: $\Phi=\Gamma /\left(\Gamma+k_{\mathrm{nr}}\right)$ and $\tau=1 /\left(\Gamma+k_{\mathrm{nr}}\right)$, where $\Gamma$ and $k_{\mathrm{nr}}$ are the radiative and nonradiative decay rates, respectively. ${ }^{127,128}$ When the structure of a fluorophore is perturbed by the interaction with a metal nanoparticle, the plasmonic coupling causes an increase in the molecular radiative decay rate by a factor of $\gamma$. Hence, the metalenhanced quantum yield $\left(\Phi_{\mathrm{M}}\right)$ and lifetime $\left(\tau_{\mathrm{M}}\right)$ become equal to: $\Phi=\gamma \Gamma /\left(\gamma \Gamma+k_{\mathrm{nr}}\right)$ and $\tau=1 /\left(\gamma \Gamma+k_{\mathrm{nr}}\right)$, where $\gamma \Gamma$ represents the effective radiative decay rate. ${ }^{\mathbf{1 2 8}}$

Very important in MEF measurements is distance between a fluorophore and a plasmonic metal structure. ${ }^{\mathbf{1 2 5 , 1 2 9}}$ Fluorescence may be highly enhanced only when the distance between the plasmonic nanoparticle and fluorophore is larger than socalled quenching distance, because for very small distances the quenching of the fluorescence occurs. ${ }^{\mathbf{1 3 0}}$ There are many methods used for controlling distance between the plasmonic structure and the fluorophore, such as the deposition of $\mathrm{SiO}_{2}$ layer or using DNA spacers. ${ }^{\mathbf{1 3 1} \mathbf{1 3 2}}$ More detailed investigations of 
the distance-dependent quenching of fluorescence (in the range between 5 and $\sim 100 \mathrm{~nm}$ ) have been carried out by Choi et al. ${ }^{133}$ They found that fluorescence quenching occurs at distances within about $15 \mathrm{~nm}$ from the Au surface, and MEF is observed at tens of nanometers beyond the range of quenching with the maximum enhancement at about $40-50 \mathrm{~nm} .^{133}$

One of the field where MEF is used in biochemical analysis is detection of DNA. ${ }^{\mathbf{1 3 4 - 1 3 6}}$ For example, in 2010 Dragan et al. used MEF for the ultra-sensitive detection of double-stranded nucleic acids. They showed that chromophore PicoGreen creates a complex with studied DNA strands and as the result of that interaction fluorescence of chromophore is enhanced about $10^{3}$ times. ${ }^{\mathbf{1 3 4}}$ However, when this complex is adsorbed on the film of silver nanoparticles deposited on glass the enhancement of the efficiency of the fluorescence is even greater than $3 \times 10^{4}$. This very large enhancement factor leads to very small detection limit of double-stranded DNA using this method. The lowest DNA concentration that Dragan et al. were able to detect was $c a$. $1 \mathrm{pg} \mathrm{ml}{ }^{-1} \cdot{ }^{134}$ Dragan et al. also observed that the MEF enhancement occurred both for small and for highly polymeric DNA which makes this procedure universal method for DNA detection. ${ }^{\mathbf{1 3 4}}$

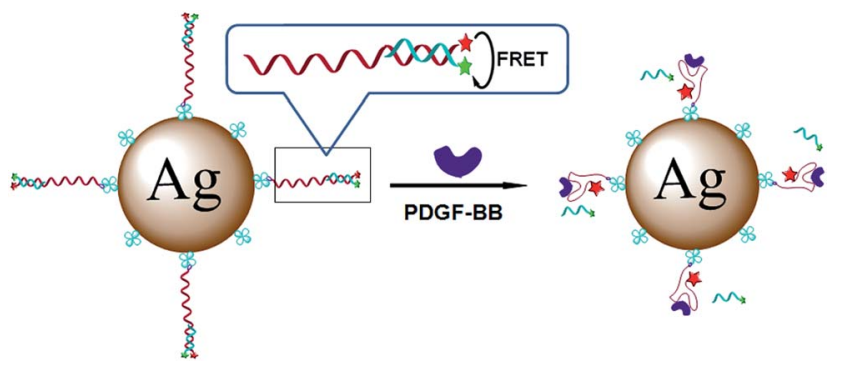

Fig. 10 Schematic presentation of the fluorescence enhancement after addition of human platelet-derived growth factor-BB. The fluorescence enhancement is due to the displacement of the quenchercarrying strands. Reprinted with permission from ref. 136. Copyright 2013 American Chemical Society.
Metal enhanced fluorescence might be also used for protein detection. As an example MEF sensor for peptide detection one can mention sensor utilizing streptavidin-functionalized silver nanoparticles with coupled fluorophore-functionalized aptamers and quencher-carrying strands hybridized in duplex. ${ }^{137}$ Such sensor may be used for detection of human platelet-derived growth factor-BB (PDGF-BB). After addition of the PDGF-BB protein, quencher-carrying strands of the duplex are displaced leading to the enhancement of the fluorescence of the fluorophore marker - see Fig. 10. ${ }^{137}$ This MEF sensor has much higher sensitivity and target specificity compared to the analogous fluorescence sensors in which plasmonic nanoparticles have not been applied. ${ }^{137,138}$

In literature there were described silver nanoparticles modified by europium(III) as nanosensors for detection of tetracycline (Tc) - antibiotic widely used in the therapy of human and animal infection. ${ }^{139}$ It was found that fluorescence intensity of the EuTc-AgNPs sensor was 4 times higher than in case of EuTc complex without silver nanoparticles. A significant advantage of this system is a fact that addition of the amino acids (Arg, Tyr, Asp, Glu, His, Lys, Cys), ascorbic acid, and glucose does not cause any fluorescence response. The detection limit for this sensor is $20 \mathrm{nM}$ and the linear relationship between the intensity of the fluorescence and the concentrations is observed in the range between $40 \mathrm{nM}$ and $8 \mu \mathrm{M}^{139}$

MEF may be also used for detection of cations of heavy metals. An example MEF sensor for cations of heavy metals has been constructed by Cheng et al. ${ }^{\mathbf{1 4 0}}$ They used both silver and gold loaded mesoporous silica materials functionalized by rhodamine as a fluorophore. The fluorescence of rhodamine at $584 \mathrm{~nm}$ was greatly enhanced after addition of $\mathrm{Hg}^{2+}$ ions, while there was no effect of other competitive ions - see Fig. 11.140 Both MEF sensors utilizing Ag or Au nanoparticles have high $\mathrm{Hg}^{2+}$ selectivity in the presence of interfering ions and have low detection limits (the detection limits of $\mathrm{Hg}^{2+}$ were determined as equal to 0.9 and $1.4 \mathrm{ppb}$ for MEF sensors utilising $\mathrm{Ag}$ and $\mathrm{Au}$ nanoparticles, respectively). ${ }^{\mathbf{1 4 0}}$ Different MEF sensor for detection of mercury ions uses gold nanoparticles capped by
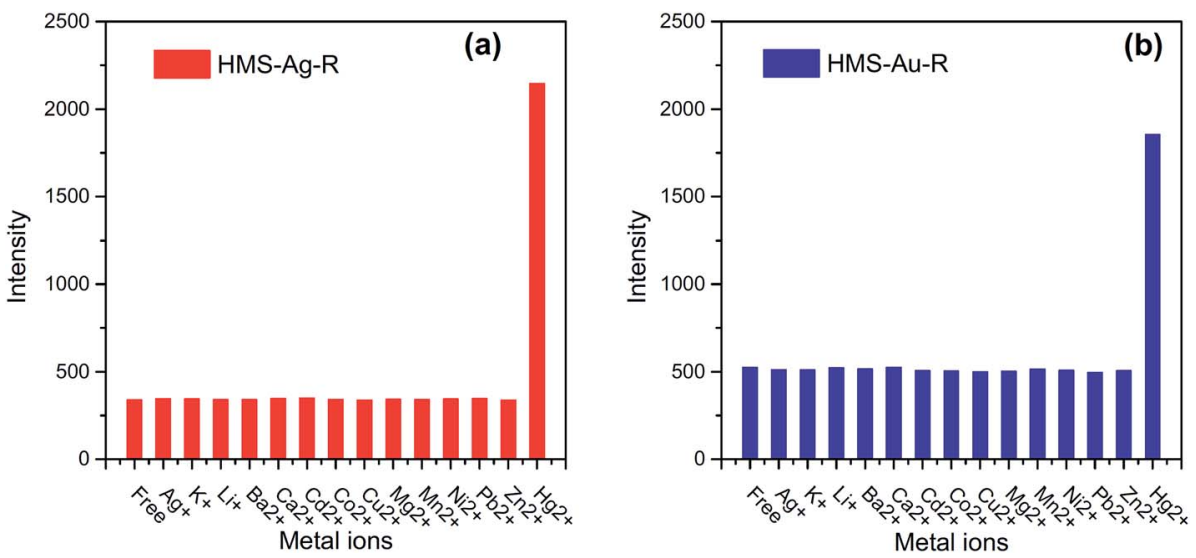

Fig. 11 The fluorescence intensity of: (a) hexagonal mesoporous silica material loaded with Ag nanoparticles and functionalized by rhodamine (HMS-Ag-R), and (b) hexagonal mesoporous silica material loaded with Au nanoparticles and functionalized by rhodamine (HMS-Au-R) in presence of other competitive cations and $\mathrm{Hg}^{2+}$. Reprinted from ref. 140 with permission from Elsevier. Copyright 2015 Elsevier. 
luminal. ${ }^{141}$ It was observed that fluorescent intensity decreasing with increasing concentrations of $\mathrm{Hg}^{2+}$ ions in a sample. This system could be use in the range between 10 and $600 \mathrm{nM}$, while limit of the detection was calculated as $1 \mathrm{nM}$. Geddes et al. observed that the fluorescence intensity of the complex of fluo-3 fluorophores with $\mathrm{Ca}^{2+}$ ions could be increased even 100-fold in the close proximity to the silver nanoparticles. ${ }^{142}$ Such system gives linear response (fluorescence vs. concentrations) in the range between 0.017 and $1.35 \mu \mathrm{M}^{142}$

MEF sensors can be also used for $\mathrm{pH}$-sensing. ${ }^{143}$ Lakowicz et al. used dextran/carboxyseminaphthofluorescein (SNAFL-2) immobilized on silver island films. ${ }^{143}$ SNAFL-2 can be used as $\mathrm{pH}$ sensor because its acid form has an emission peak at $552 \mathrm{~nm}$ while its base form emits $665 \mathrm{~nm}$ light. Silver nanostructures significantly enhance intensity of the fluorophore's fluorescence (in this case about 40 times). ${ }^{143}$ The $\mathrm{pH}$ values were estimated from the intensity ratio of the SNAFL-2 emission at 590 and $555 \mathrm{~nm}$ (in base and acid form). ${ }^{143}$

Another interesting modification of MEF is MAMEF (microwave-accelerated metal-enhanced fluorescence). In this approach the effect of the fluorescence enhancement near to the metallic surface is combined with the use of the low energy microwave radiation. The used microwave does not damp the fluorescence yield increase, the MAMEF effect is due to the increased mass transport of the studied molecules to the metallic surface which results in the higher fluorescence and shorter measurement time. MAMEF has been used, for example, for protein, DNA and bacteria's cells detection. ${ }^{\mathbf{1 4 4 - 1 4 7}}$ In the case of DNA detection, Geddes et al. used as DNA sensor thiol-functionalized oligonucleotides immobilized on silver nanostructures deposited on the glass surface. ${ }^{\mathbf{1 4 5}}$ In this approach, after addition of the complementary fluoresceinlabeled DNA strand, hybridization of this oligonucleotide and the one on the silver surface has been carried out. This reaction leads to the metal-enhanced fluorescein emission (MEF effect) as the probe is brought into close proximity to the silver upon hybridization. Using of the microwave irradiation induces stronger fluorescence enhancement and enables 600 times decreasing of the measurement time (less than $20 \mathrm{~s}$ ) compared to sample without microwave irradiation. ${ }^{145}$

\section{Conclusions}

In this review article we have focused on analytical techniques utilising plasmonic properties of $\mathrm{Ag}$ and $\mathrm{Au}$ nanoparticles (for examples of such analysis see Table 1). Presented analytical techniques include methods based on the chance of the plasmonic properties of nanoparticles (for example caused by their

Table 1 Example analysis utilizing plasmonic nanoparticles

\begin{tabular}{|c|c|c|c|c|c|}
\hline The method & Analyte & Nanoparticles & Linear range & Limit of detection (LOD) & Ref. \\
\hline \multirow[t]{8}{*}{ UV-vis } & $\mathrm{Cd}^{2+}, \mathrm{Hg}^{2+}, \mathrm{Pb}^{2+}$ & $\mathrm{Au}$ & $50-200 \mu \mathrm{M}$ & $2.5 \mathrm{nM}$ & 36 \\
\hline & $\mathrm{Li}^{+}$ & $\mathrm{Au}$ & $10-100 \mathrm{mM}$ & & 37 \\
\hline & $\mathrm{Pt}^{2+}$ & $\mathrm{Au}$ & $0.6-12.5 \mu \mathrm{M}$ & $150 \mathrm{nM}$ & 39 \\
\hline & $\mathrm{Hg}^{2+}$ & $\mathrm{Au}$ & $0.5-10 \mathrm{nM}$ & $0.26 \mathrm{nM}$ & 42 \\
\hline & $\mathrm{Mn}^{2+}$ & $\mathrm{Ag}$ & $0.3-60 \mu \mathrm{M}$ & $20 \mathrm{nM}$ & 43 \\
\hline & DNA & $\mathrm{Au}$ & $1 \mathrm{pM}$ to $10 \mathrm{nM}$ & & 57 \\
\hline & Phosgene & $\mathrm{Au}$ & $15-45 \mu \mathrm{M}$ & $420 \mathrm{nM}$ & 52 \\
\hline & Dopamine & $\mathrm{Ag}$ & $0.2-300 \mu \mathrm{M}$ & $0.2 \mu \mathrm{M}$ & 48 \\
\hline \multirow[t]{4}{*}{ SERS } & Thiram & Ag nanorods & $10 \mu \mathrm{M}$ to $10 \mathrm{mM}$ & $10 \mathrm{ng} \mathrm{cm}^{-2}$ & 81 \\
\hline & Thiabendazole & Au nanostars & $0.1-100 \mu \mathrm{M}$ & $0.1 \mu \mathrm{M}$ & 82 \\
\hline & Avidin & $\mathrm{Au}$ & $10 \mathrm{ng} \mathrm{ml}^{-1}$ to $1 \mu \mathrm{g} \mathrm{ml}^{-1}$ & $10 \mathrm{ng} \mathrm{ml}^{-1}$ & 96 \\
\hline & $\mathrm{Hg}^{2+}$ & Au nanostars dimers & $2 \mathrm{pg}$ to $1 \mathrm{ng}$ & $0.8 \mathrm{pg} \mathrm{ml}^{-1}$ & 149 \\
\hline \multirow[t]{5}{*}{ SEIRA } & $p$-Mercaptoaniline & Au nanoshells & $10-1000 \mu \mathrm{M}$ & $1 \mu \mathrm{M}$ & 150 \\
\hline & Tyrosine & $\mathrm{Ag}$ & $10-120 \mu \mathrm{M}$ & $10 \mu \mathrm{M}$ & 151 \\
\hline & $p$-Nitrobenzoic acid & $\mathrm{Ag}$ & $17-1700 \mathrm{ng}$ & $17 \mathrm{ng}$ & 152 \\
\hline & $p$-Nitrobenzoic acid & Ag nanorods & $10-1800 \mathrm{ng} \mathrm{cm}^{-2}$ & $0.08 \mathrm{ng} \mathrm{cm}^{-2}$ & 153 \\
\hline & Crystal violet & Au nanostars & $4-25 \mathrm{mg} \mathrm{l}^{-1}$ & $4 \mathrm{mg} \mathrm{l}^{-1}$ & 154 \\
\hline \multirow[t]{6}{*}{ MEF } & DNA & $\mathrm{Ag}$ & $1 \mathrm{nM}$ to $1 \mathrm{mM}$ & $1 \mathrm{pg} \mathrm{ml}^{-1}$ & 134 \\
\hline & $\mathrm{Hg}^{2+}$ & $\mathrm{Au}$ & $10-600 \mathrm{nM}$ & $1 \mathrm{nM}$ & 141 \\
\hline & $\mathrm{Hg}^{2+}$ & $\mathrm{Ag}$ & $10-110 \mathrm{ppb}$ & $0.9 \mathrm{ppb}$ & 140 \\
\hline & $\mathrm{Hg}^{2+}$ & $\mathrm{Au}$ & $10-100 \mathrm{ppb}$ & $1.14 \mathrm{ppb}$ & 140 \\
\hline & $\mathrm{Hg}^{2+}$ & $\mathrm{Au}$ & $1 \mathrm{nM}$ to $1 \mathrm{mM}$ & $1 \mathrm{nM}$ & 155 \\
\hline & $\mathrm{Ca}^{2+}$ & $\mathrm{Ag}$ & $17 \mathrm{nM}$ to $135 \mathrm{nM}$ & $17 \mathrm{nM}$ & 142 \\
\hline
\end{tabular}


aggregation) and techniques utilising increasing of the efficiency of various optical processes in the proximity of plasmonic nanoparticles, which includes surface-enhanced Raman scattering (SERS), surface enhanced infra-red absorption (SEIRA), and metal-enhanced fluorescence (MEF). The basic theory concerning interaction of the electromagnetic radiation with the plasmonic nanoparticles is also briefly presented. Analytical methods described in this article belong to the most sensitive analytical tools. Fluorescence techniques allow in some cases for reliable observation of the signal even from a single molecule. Also by utilizing plasmonic nanoresonators the Raman scattering cross-sections can be sometimes increased to the level making possible observation of the Raman spectra of a single molecule. Wide potential field of applications (especially in the medical diagnostic) of techniques utilising surface plasmon resonance suggests that the number of applications of plasmonic methods will significantly increase in the near future.

\section{Acknowledgements}

This work was financed from the funds of the National Science Centre (Poland) allocated on the basis of the decision number DEC-2013/11/B/ST5/02224. AK thanks the Faculty of Chemistry, University of Warsaw for the financial support.

\section{References}

1 A. Trügler, Optical Properties of Metallic Nanoparticles, Springer International Publishing, Heidelberg, 2016.

2 M. Pelton and G. W. Bryant, Introduction to MetalNanoparticle Plasmonics, John Wiley \& Sons, Weinheim, 2013.

3 A. Kudelski, Electrochemical preparation of nanoresonators, in Handbook of Nanoelectrochemistry, ed. M. Aliofkhazraei and A. S. H. Makhlouf, Springer International Publishing, Heidelberg, 2016, pp. 47-69.

4 P. G. Etchegoin and E. C. Le Ru, Basic electromagnetic theory of SERS, in Surface Enhanced Raman Spectroscopy: Analytical, Biophysical and Life Science Applications, ed. S. Schlücker, Wiley-VCH, New York, 2011, pp. 1-37.

5 J. P. Kottmann, O. J. F. Martin, D. R. Smith and S. Schultz, Chem. Phys. Lett., 2001, 341, 1.

6 I. A. Larmour and D. Graham, Analyst, 2011, 136, 3831.

7 M. Li, S. K. Cushing and N. Wu, Analyst, 2015, 140, 386.

8 L. M. Luiz-Marzan, Mater. Today, 2004, 7, 26.

9 M. G. Guzmán, J. Dille and S. Godet, Int. J. Chem. Biol. Eng., 2009, 104, 2-3.

10 K. L. Kelly, E. Coronado, L. L. Zhao and G. C. Schatz, J. Phys. Chem. B, 2003, 107, 668.

11 S. Yoo and Q. H. Park, Opt. Express, 2012, 20, 16480.

12 A. R. Sadrolhosseini, A. S. M. Noor and M. Moksin, Application of surface plasmon resonance based on a metal nanoparticle, in Plasmonics - Principles and Applications, ed. K. Y. Kim, InTech, 2012, pp. 253-282.

13 M. Rycenga, C. M. Cobley, J. Zeng, W. Li, C. H. Moran, Q. Zhang, D. Qin and Y. Xia, Chem. Rev., 2011, 111, 3669.
14 X. Zhang, Y. L. Chen, R. S. Liu and D. P. Tsai, Rep. Prog. Phys., 2013, 76, 046401.

15 L. Polavarapu, S. Mourdikoudis, I. Pastoriza-Santos and J. Pérez-Juste, CrystEngComm, 2015, 17, 3727.

16 L. Polavarapu and L. M. Liz-Marzan, Nanoscale, 2013, 5, 4355.

17 C. Xue and C. A. Mirkin, Angew. Chem., Int. Ed., 2007, 46, 2036.

18 J. C. Scaiano and K. G. Stamplecoskie, Photochem. Photobiol., 2012, 88, 762.

19 I. Pastoriza-Santos and L. M. Liz-Marzán, J. Mater. Chem., 2008, 18, 1724.

20 R. Jin, Y. C. Cao, E. Hao, G. S. Métraux, G. C. Schatz and C. A. Mirkin, Nature, 2003, 425, 487.

21 E. K. Payne, K. L. Shuford, S. Park, G. C. Schatz and C. A. Mirkin, J. Phys. Chem. B, 2006, 110, 2150.

22 J. Krajczewski, V. Joubert and A. Kudelski, Colloids Surf., A, 2014, 456, 41.

23 D. Ghosh and N. Chattopadhyay, Opt. Photonics J., 2013, 3, 18.

24 A. M. Schwartzberg, T. Y. Olson, C. E. Talley and J. Z. Zhang, J. Phys. Chem. B, 2006, 110, 19935.

25 H. Abdulrahman, J. Krajczewski, D. Aleksandrowska and A. Kudelski, J. Phys. Chem. C, 2015, 119, 20030.

26 E. Hao, G. C. Schatz and J. T. Hupp, J. Fluoresc., 2004, 14, 331.

27 E. Hao and G. C. Schatz, J. Chem. Phys., 2004, 120, 357.

28 K. A. Stoerzinger, W. Hasan, J. Y. Lin, A. Robles and T. W. Odom, J. Phys. Chem. Lett., 2010, 1, 1046.

29 J. Yang, F. Ren, X. Chong, D. Fan, S. Chakravarty, Z. Wang, R. T. Chen and A. X. Wang, Photonics, 2014, 1, 380.

30 P. Pavaskar, J. Theiss and S. B. Cronin, Opt. Express, 2012, 20, 14656.

31 D. Radziuk and H. Moehwald, Phys. Chem. Chem. Phys, 2015, 17, 21072.

32 S. L. Kleinman, E. Ringe, N. Valley, K. L. Wustholz, E. Phillips, K. A. Scheidt, G. C. Schatz and R. P. van Duyne, J. Am. Chem. Soc., 2011, 133, 4115.

33 L. Polavarapu, J. Pérez-Juste, Q.-H. Xu and L. M. Liz-Marzán, J. Mater. Chem. C, 2014, 2, 7460.

34 A. Lee, G. F. S. Andrade, A. Ahmed, M. L. Souza, N. Coombs, E. Tumarkin, K. Liu, R. Gordon, A. G. Brolo and E. Kumacheva, J. Am. Chem. Soc., 2011, 133, 7563.

35 D. K. Lim, K. S. Jeon, H. M. Kim, J. M. Nam and Y. D. Suh, Nat. Mater., 2010, 9, 60.

36 Y. Kim, R. C. Johnson and J. T. Hupp, Nano Lett., 2001, 1, 165.

37 S. O. Obare, R. E. Hollowell and C. J. Murphy, Langmuir, 2002, 26, 10407.

38 Y. Zhou, S. Wang, K. Zhang and X. Jiang, Angew. Chem., Int. Ed., 2008, 47, 7454.

39 D. Fan, Q. Zhai, W. Zhou, X. Zhu, E. Wang and S. Dong, Biosens. Bioelectron., 2016, 85, 771.

40 L. J. Miao, J. W. Xin, Z. Y. Shen, Y. J. Zhang, H. Y. Wang and A. G. Wu, Sens. Actuators, B, 2013, 176, 906.

41 M. Shellaiah, T. Simon, K. W. Sun and F. H. Ko, Sens. Actuators, B, 2016, 226, 44. 
42 Y. Zhao, L. Gui and Z. Chen, Sens. Actuators, B, 2017, 241, 262.

43 Y. He and X. Zhang, Sens. Actuators, B, 2016, 222, 320.

44 Y. X. Gao, J. W. Xin, Z. Y. Shen, W. Pan, X. Li and A. G. Wu, Sens. Actuators, B, 2013, 181, 288.

45 X. J. Yang, Y. B. Yu and Z. Q. Gao, ACS Nano, 2014, 8, 4902. 46 X. J. Yang, Y. Q. Ren and Z. Q. Gao, Chem.-Eur. J., 2015, 21, 988.

47 L. Guo, Y. Xu, A. R. Ferhan, G. Chen and D. H. Kim, J. Am. Chem. Soc., 2013, 135, 12338.

48 D. R. Raj, S. Prasanth, T. V. Vineeshkumar and C. Sudarsanakumar, Sens. Actuators, B, 2016, 224, 600.

49 B. Li, H. Wei and S. Dong, Chem. Commun., 2007, 50, 73.

50 R. Elghanian, J. Storhoff, R. C. Mucic, R. L. Letsinger and C. A. Mirkin, Science, 1997, 277, 1078.

51 L. Li and L. Rothberg, Proc. Natl. Acad. Sci. U. S. A., 2004, 101, 14036.

52 D. Feng, Y. Zhang, W. Shi, X. Lia and H. Ma, Chem. Commun., 2010, 46, 9203.

53 W. Zhou, Y. Ma, H. Yang, Y. Ding and X. Luo, Int. J. Nanomed., 2011, 6, 381.

54 C. D. Medley, J. E. Smith, Z. W. Tang, Y. R. Wu, S. Bamrungsap and W. H. Tan, Anal. Chem., 2008, 80, 1067.

55 R. Aroca, Surface-enhanced vibrational spectroscopy, John Wiley \& Sons Ltd, Chichester, 2006.

56 M. Fleischmann, P. J. Hendra and A. J. McQuillan, Chem. Phys. Lett., 1974, 26, 163.

57 D. L. Jeanmaire and R. P. van Duyne, J. Electroanal. Chem., 1977, 84, 1.

58 M. G. Albrecht and J. A. Creighton, J. Am. Chem. Soc., 1974, 99, 5215.

59 M. Kerker, D. S. Wang and H. Chew, Appl. Opt., 1980, 19, 4159.

60 R. C. Maher, L. F. Cohen and P. Etchegoin, Chem. Phys. Lett., 2002, 352, 378.

61 S. Schlucker, Angew. Chem., Int. Ed., 2014, 53, 4756.

62 M. Procházka, Surface-Enhanced Raman Spectroscopy, Springer International Publishing, 2016.

63 J. R. Lombardi, R. L. Birke, T. Lu and J. Xu, J. Chem. Phys., 1986, 84, 4174.

64 M. Osawa, N. Matsudam, K. Yoshii and I. Uchida, J. Phys. Chem., 1994, 98, 12702.

65 J. F. Arenas, I. López-Tocón, M. S. Woolley, J. C. Otero and J. I. Marcos, J. Raman Spectrosc., 1998, 29, 673.

66 A. B. Zrimsek, N. L. Wong and R. P. van Duyne, J. Phys. Chem. C, 2016, 120, 5133.

67 L. Li, T. Hutter, U. Steinerc and S. Mahajan, Analyst, 2013, 138, 4574.

68 S. Nie and S. R. Emory, Science, 1997, 275, 1102.

69 L. Zhang, H. Liu, L. Chen, P. Guan, B. Chen, T. Fujita, Y. Yamaguchi, H. Iwasaki, Q.-K. Xue and M. Chen, RSC Adv., 2016, 6, 2882.

70 P. Etchegoin, R. C. Maher, L. F. Cohen, H. Hartigan, R. J. C. Brown, M. J. T. Milton and J. C. Gallop, Chem. Phys. Lett., 2003, 375, 84.

71 A. Kudelski, Chem. Phys. Lett., 2006, 427, 206.

72 A. Kudelski, J. Raman Spectrosc., 2007, 38, 1494.
73 K. Chen, M. Leona, K. C. Vo-Dinh, F. Yan, M. B. Wabuyele and T. Vo-Dinh, J. Raman Spectrosc., 2006, 37, 520.

74 X. Lian, X. J. Zhan, T. T. You, G. S. Wang, P. G. Yin and L. Guo, CrystEngComm, 2016, 18, 7805.

75 M. Leona, J. Stenger and E. Ferloni, J. Raman Spectrosc., 2006, 37, 981.

76 J. F. Li, Y. F. Huang, Y. Ding, Z. L. Yang, S. B. Li, X. S. Zhou, F. R. Fan, W. Zhang, Z. Y. Zhou, D. Y. Wu, B. Ren, Z. L. Wang and Z. Q. Tian, Nature, 2010, 464, 392.

77 A. Kudelski and S. Wojtysiak, J. Phys. Chem. C, 2012, 116, 16167.

78 X. D. Lin, V. Uzayisenga, J. F. Li, P. P. Fang, D. Y. Wu, B. Ren and Z. Q. Tian, J. Raman Spectrosc., 2012, 43, 40.

79 V. Uzayisenga, X. D. Lin, L. M. Li, J. R. Anema, Z. L. Yang, Y. F. Huang, H. X. Lin, S. B. Li, J. F. Li and Z. Q. Tian, Langmuir, 2012, 28, 9140.

80 H. B. Abdulrahman, K. Kołątaj, P. Lenczewski, J. Krajczewski and A. Kudelski, Appl. Surf. Sci., 2016, 388, 704.

81 S. Kumar, P. Goel and J. P. Singh, Sens. Actuators, B, 2017, 241, 577.

82 A. Shiohara, J. Langer, L. Palavarapu and L. Liz-Marzan, Nanoscale, 2014, 6, 9817.

83 X. Zhang, M. A. Young, O. Lyandres and R. P. van Duyne, J. Am. Chem. Soc., 2005, 127, 4484.

84 X. Zhang, J. Zhao, A. V. Whitney, J. E. Elam and R. P. van Duyne, J. Am. Chem. Soc., 2006, 128, 10304.

85 S. E. J. Bell, J. N. Mackle and N. M. S. Sirimuthu, Analyst, 2005, 130, 545.

86 D. P. Cowcher, Y. Xu and R. Goodacre, Anal. Chem., 2013, 85, 3297.

87 W. R. Premasiri, D. T. Moir, M. S. Klempner, N. Krieger, G. Jones and L. D. Ziegler, J. Phys. Chem. B, 2005, 109, 312.

88 W. Q. Wang, V. Hynninen, L. Qiu, A. W. Zhang, T. Lemmad, N. N. Zhang, H. H. Ge, J. Toppari, V. P. Hytönen and J. Wang, Sens. Actuators, B, 2017, 239, 515.

89 R. Jarvis, S. Clarke and R. Goodacre, Top. Appl. Phys., 2006, 103, 397.

90 R. M. Jarvis and R. Goodacre, Anal. Chem., 2004, 76, 40.

91 M. Harz, P. Rosch, K. D. Peschke, O. Ronneberger, H. Burkhardt and J. Popp, Analyst, 2005, 130, 1543.

92 R. M. Jarvis, A. Brooker and R. Goodacre, Anal. Chem., 2004, 76, 5198.

93 P. Rosch, M. Harz, M. Schmitt, K. Peschke, O. Ronneberger, H. Burkhardt, H. Motzkus, M. Lankers, S. Hofer, H. Thiele and J. Popp, Appl. Environ. Microbiol., 2005, 71, 1626.

94 R. M. Jarvis, A. Brooker and R. Goodacre, Faraday Discuss., 2006, 132, 281.

95 T. Lemma, A. Saliniemi, V. Hynninen, V. P. Hytönen and J. J. Toppari, Vib. Spectrosc., 2016, 83, 36.

96 C. Ruan, W. Wang and B. Gu, Anal. Chem., 2006, 78, 3379. 97 C. E. Talley, L. Jusinski, C. W. Hollars, S. M. Lane and T. Huser, Anal. Chem., 2004, 76, 7064.

98 J. Kneipp, H. Kneipp, B. Wittig and K. Kneipp, Nano Lett., 2007, 7, 2819.

99 S. Zong, Z. Wang, J. Yang and Y. Cui, Anal. Chem., 2011, 83, 4178. 
100 J. K. Lim and S. W. Joo, Appl. Spectrosc., 2006, 60, 847.

101 P. Piotrowski and J. Bukowska, Sens. Actuators, B, 2015, 221, 700.

$102 \mathrm{~J} . \mathrm{Li}, \mathrm{L}$. Chen, T. Lou and Y. Wang, ACS Appl. Mater. Interfaces, 2011, 3, 3936.

103 S. S. R. Dasary, Y. K. Jones, S. L. Barnes, P. C. Ray and A. K. Singh, Sens. Actuators, B, 2016, 224, 65.

104 S. Abdali and E. W. Blanch, Chem. Soc. Rev., 2008, 37, 980.

105 H. Kneipp, J. Kneipp and K. Kneipp, Anal. Chem., 2006, 78, 1363.

106 K. Osinska, M. Pecul and A. Kudelski, Chem. Phys. Lett., 2010, 496, 86.

107 S. O. Pour, S. E. J. Bellb and E. W. Blanch, Chem. Commun., 2011, 47, 4754.

108 A. Hartstein, J. R. Kirtley and J. C. Tsang, Phys. Rev. Lett., 1980, 45, 201.

109 M. Osawa and M. Ikeda, J. Phys. Chem., 1991, 95, 9914.

110 R. F. Aroca, D. J. Ross and C. Domingo, Appl. Spectrosc., 2004, 58, 324A.

111 G. P. C. Rao and J. Yang, Appl. Spectrosc., 2015, 69, 37.

112 K. P. Ishida and P. R. Griffiths, Anal. Chem., 1994, 66, 522.

113 Z. Zhang, T. Imae, H. Sato, A. Watanabe and Y. Ozaki, Langmuir, 2001, 17, 4564.

114 A. Hatta, T. Ohshima and W. Suëtaka, Appl. Phys. A, 1982, 29, 71.

115 Y. Nishikawa, K. Fujiwara and T. Shima, Appl. Spectrosc., 1990, 44, 691.

116 M. Osawa, K. Ataka, M. Ikeda, H. Uchihara and R. Namba, Anal. Sci., 1991, 7, 503.

117 S. Prati, M. Quaranta, G. Sciutto, I. Bonacini, L. Litti, M. Meneghetti and R. Mazzeo, Heritage Sci., 2014, 2, 28.

118 S. Prati, S. Sciutto, I. Bonacini and R. Mazzeo, Top. Curr. Chem., 2016, 374, 129.

119 V. F. Chekhun, G. I. Solyanik, G. I. Kulik, V. P. Tryndiak, I. N. Todor, G. I. Dovbeshko and O. P. Repnytska, J. Exp. Clin. Cancer Res., 2002, 21, 599.

120 G. I. Dobbeshko, V. I. Chegel, N. Y. Gridina, O. P. Repnytska, Y. M. Shirshob, V. P. Tryndiak, I. M. Todor and G. I. Solyanik, Biopolymers, 2002, 67, 470.

121 C. Brown, Y. Li, J. Seelenbinder, P. Pivarnik, A. Rand, S. Letcher, M. Platek and O. Gregory, Anal. Chem., 1998, 70, 2991.

122 K. Ataka, F. Giess, W. Knoll, R. Naumann, S. HaberPohlmeier, B. Richter and J. Heberle, J. Am. Chem. Soc., 2004, 49, 16199.

123 H. Y. N. Holman, D. L. Perry and J. C. Hunter-Cevera, J. Microbiol. Methods, 1998, 34, 59.

124 Q. Cai, F. Hu, S.-T. Lee, F. Liao, Y. Li and M. Shao, Appl. Phys. Lett., 2015, 106, 023107.

125 W. Q. Lim and Z. Gao, Nano Today, 2016, 11, 168.

126 C. Geddes and J. Lakowicz, J. Fluoresc., 2012, 12, 121.

127 J. R. Lakowicz, Principles of Fluorescence Spectroscopy, Plenum Publishing Corporation, New York, NY, USA, 2nd edn, 1999.
128 J. Asselin, M. L. Viger and D. Boudreau, Adv. Chem., 2014, 2014, 812313.

129 J. R. Lakowicz, Anal. Biochem., 2005, 337, 171.

130 H. Mishra, B. L. Mali, J. Karolin, A. I. Dragan and C. D. Geddes, Phys. Chem. Chem. Phys., 2013, 15, 19538.

131 A. V. Sorokin, A. A. Zabolotskii, N. V. Pereverzev, I. I. Bespalova, S. L. Yefimova, Y. V. Malyukin and A. I. Plekhanov, J. Phys. Chem. C, 2015, 119, 2743.

132 Z. Zhou, H. Huang, Y. Chen, F. Liu, C. Z. Huang and N. Li, Biosens. Bioelectron., 2014, 52, 367.

133 Y. S. Chi, H. R. Byon, B. S. Lee, B. Kong, H. C. Choi and I. S. Choi, Adv. Funct. Mater., 2008, 18, 3395.

134 A. I. Dragan, E. S. Bishop, J. R. Casas-Finet, R. J. Strouse, M. A. Schenerman and C. D. Geddes, J. Immunol. Methods, 2010, 362, 95.

135 J. Lakowicz, J. Malicka and I. Gryczyński, BioTechniques, 2003, 34, 62 .

136 J. Lakowicz and C. Sabanayagam, Nucleic Acids Res., 2007, 35,1 .

137 H. Li, M. Wang, C. Wang, W. Li, W. Qiang and D. Xu, Anal. Chem., 2013, 85, 4492.

138 H. Takayama, Y. Miyake, K. Nouso, F. Ikeda, H. Shiraha, A. Takaki, H. Kobashi, K. Yamamoto and K. Yanamoto, J. Gastroenterol. Hepatol., 2011, 26, 116.

139 H. Tan and Y. Chen, Sens. Actuators, B, 2012, 173, 262.

140 Z. Cheng, G. Li and M. Liu, Sens. Actuators, B, 2015, 212, 495.

141 Q. Li, J. Wang and Y. He, Sens. Actuators, B, 2016, 231, 64.

142 N. Bondre, Y. Zhang and C. D. Geddes, Sens. Actuators, B, 2011, 152, 82.

143 K. Aslan, J. R. Lakowicz, H. Szmacinski and C. D. Geddes, J. Fluoresc., 2005, 15, 37.

144 K. Aslan and C. D. Geddes, Anal. Chem., 2005, 77, 8057.

145 K. Aslan, S. Malyn, G. Bector and C. D. Geddes, Analyst, 2007, 132, 1122.

146 Y. Zhang, P. Agreda, S. Kelley, C. Gaydos and C. D. Geddes, IEEE Trans. Biomed. Eng., 2011, 58, 781.

147 S. M. Tennant, Y. Zhang, J. E. Galen, C. D. Geddes and M. M. Levine, PLoS One, 2011, 6, e18700.

148 O. Peron, E. Rinnert, T. Toury, M. L. de la Chapelle and C. Compere, Analyst, 2011, 136, 1018.

149 W. Ma, M. Sun, L. Xu, L. Wang, H. Kuang and C. Xu, Chem. Commun., 2013, 49, 4989.

150 J. Kundub, F. Lec, P. Nordlanderc and N. J. Halas, Chem. Phys. Lett., 2008, 452, 115.

151 G. P. C. Rao and J. Yang, Anal. Bioanal. Chem., 2011, 401, 2935.

152 H. D. Wanzenböck, B. Mizaikoff, N. Weissenbacher and R. Kellner, J. Mol. Struct., 1997, 410, 535.

153 C. L. Leverette, S. A. Jacobs, S. Shanmukh, S. B. Chaney, R. A. Dluhy and Y. P. Zhao, Appl. Spectrosc., 2006, 60, 906.

154 O. Bibikova, J. Haas, A. I. López-Lorente, A. Popov, M. Kinnunen, I. Meglinski and B. Mizaikoff, Analyst, 2017, 142, 951.

155 B. C. Ye and B. C. Yin, Angew. Chem., Int. Ed., 2008, 47, 8386. 